ISABELLA CUNHA

\title{
PARTICIPAÇÃO DO RECEPTOR P2X7 NO CONTROLE DAS POPULAÇÕES DE CÉLULAS TFH E B ESPLÊNICAS E NA PROTEÇÃO CONTRA O Plasmodium yoelii 17XNL
}

Dissertação apresentada ao Programa de Pós-Graduação em Imunologia do Instituto de Ciências Biomédicas da Universidade de São Paulo, para a obtenção do Título de Mestre em Ciências.

São Paulo 


\title{
ISABELLA CUNHA
}

\section{PARTICIPAÇÃO DO RECEPTOR P2X7 NO CONTROLE DAS POPULAÇÕES DE CÉLULAS TFH E B ESPLÊNICAS E NA PROTEÇÃO CONTRA O Plasmodium yoelii 17XNL}

\author{
Dissertação apresentada ao Programa de \\ Pós-Graduação em Imunologia do Instituto de \\ Ciências Biomédicas da Universidade de São \\ Paulo, para a obtenção do Título de Mestre \\ em Ciências. \\ Área de concentração: Imunologia \\ Orientador (a): Prof (a). Dra. Maria Regina D' \\ Império Lima \\ Versão corrigida
}

São Paulo 


\section{CATALOGAÇÃO NA PUBLICAÇÃO (CIP) \\ Serviço de Biblioteca e informação Biomédica do Instituto de Ciências Biomédicas da Universidade de São Paulo}

Ficha Catalográfica elaborada pelo(a) autor(a)

Cunha, Isabella

Participaçăo do receptor $\mathrm{P} 2 \mathrm{X} 7$ no controle das populaçōes de células Tfh e B esplênicas e na proteção contra o Plasmodium yoelii 17XNL / Isabella

Cunha; orientadora Maria Regina D\' Império Lima. - São Paulo, 2018.

$70 \mathrm{p}$.

Dissertação (Mestrado) ) -- Universidade de São Paulo, Instituto de Ciências Biomédicas.

1. Plasmodium yoelii 17XNL. 2. Receptor P2X7. 3. Células Tfh. 4. Células B do centro germinativo. 5 . Anticorpos. I. D\' Império Lima, Maria Regina, orientador. II. Título. 


\section{UNIVERSIDADE DE SÃO PAULO \\ INSTITUTO DE CIÊNCIAS BIOMÉDICAS}

Candidata: Isabella Cunha

Título da Dissertação: Participação do receptor P2X7 no controle das populações de células Tfh e B esplênicas e na proteção contra o Plasmodium yoelii 17XNL.

Orientador: Prof. Dra. Maria Regina D’ Império Lima

A Comissão Julgadora dos trabalhos de Defesa da Dissertação de Mestrado, em sessão pública realizada a , considerou a candidata

\section{( ) Aprovada ( ) Reprovada}

Examinador(a): Assinatura:

Nome:

Instituição:

Examinador(a): Assinatura:

Nome:

Instituição:

Examinador(a): Assinatura:

Nome:

Instituição:

Presidente: Assinatura:

Nome:

Instituição: 


\author{
CONISSÄO DE ĖICA NO USO OE ANIMAIS \\ NGTITUTO DECIENCIAS HIOMEDICAS \\ UNYYERSIDADE DE SÄOPAMLO
}

ICBUSP

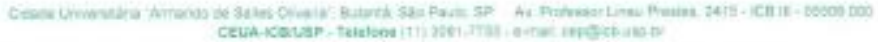

\title{
CERTIFICADO
}

Certificamos que a prajeto intitulado "Importancia do receptor p2x7 na celula t heiper foliculor durante a infeccâo pelo plasmodium chabgudi chaboudil(os)", registrado sab a protocolo n? 109/2015, que envolve a produsào, manutençio e/ou utilização de animais pertencentes ao filo Chordata, subfilo Vertebrata (exceto o homem), para fins de pesquisa cientifica, encontra-se de acordo com os preceitos da Lei $\pi^{2} 11.794$, de 8 de outubro de 2008, do Decreto $a^{2} 6.899$, de 15 de julho de 2009 , e com as normas editadas peio Conselho Nacional de Controle e Experimentaçio Animal (CONCEA). Ante esta conformidade, o referido projeto foi avaliado e aprovado em $07 / 12 / 2015$ pela COMISSẮ DE ÉTICA NO USO DE ANIMAIS do Instituto de Ciénclas Biomedicas da Universidade de Săo Paulo (CEUA-IC8/USP), outorgando esta licenca de uso de animais tem validade de 04 (quatro) anos a partir da data de aprovaça.

- Imvestigador Principal: Dr.(a.) Maria Regina D'Imperio Lima

- Membros da Equipe: Renan Siqueira (Pós-zraduando)

Havendo interesse na renovaçåo do projeto, a solicitação deverá ser protocolada pela Secretaria da CEUA.ICB/USP até o último dia de validade da atual proposta. Apos esta data uma nova proposta deverà ser encaminharta.

\section{CERTIFICATE}

We herpby certify that the groject entitled "importance of $p 2 x 7$ receptor on $t$ helper follicular cell during plesmodium chobaudl chaboudi (as) infection", protocol $n^{*} 109 / 2015$, which involves the production, maintenance and/or use of animals belonging to the phylum Chordata, subphylum Vertebrata lexcept human], for scientific research purposes, is in accardance with the provisions of the Law $n^{2} 11.794$ passed on October $8^{\text {th }}, 2008$, Decree $n^{2} 6899$ passed on July $15^{10}, 2009$, and the rules issued by the National Councl for Control and Animal Experimentation (CONCEA). ACcording to this legislation, the project was evaluated and approved on $12 / 7 / 2015$ by the ETHICS COMMITTEE ON ANIMAL USE, Institute of Biomedical Sciences, University of Sab Paulo [CEUA-ICB/USP], and the license for animal use is valid for 04 (four) years from the date of approval

- Principal Investigator. Dr-(a.) Maria Regina D'Imperio Lima

- Team members: Renan Siqueira (Graduate Student)

If a renewal of the project is intended, the request must be submitted to the CEUA-ICB/USP secretary before the expiration of the current proposal. After this date, a new proposal must be prepared.

\begin{tabular}{|c|l|l|l|c}
\hline Espécie/Species & Linhagem/Strain & Sexo/Gender & Idade-Peso/Age-Weight & Total \\
\hline Mus musculus & C578u/s & Fémea/Female & $6-8$ semanas/weeks & 334 \\
& C578L//5 (P2X7R/4) & Fêmea/Female & $6-8$ semanas/weeks & 334 \\
\hline
\end{tabular}

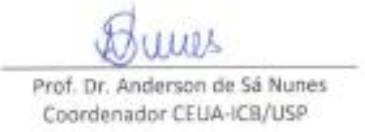

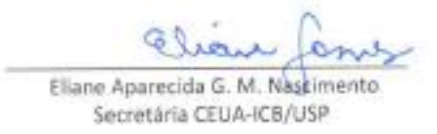


COMISSAXO DE ETICA NO USO DE ANIMAIS

INSTITUTO DE CIENCIAS BIOMÉDICAS

UNIVERSIDADE DE SẢO PAULO

ICBUSP

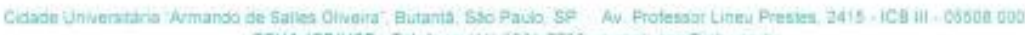

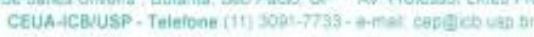

\section{CERTIFICADO}

Certificamos que o projeto intitulado "Participoçāo do receptor P2X7 na differenciaçáo e morte das células $T f h$, durante o desenvolvimento da malária experimental, registrado sob o protocolo n? $45 / 2017$, que envolve a produçăo, manutençăo e/ou utilização de animas pertencentes ao filo Chordata, subfilo Vertebrata (exceto o homem), para fins de Pesquiso Cientifico, encontra-se de acordo com os preceitos da Lei ne 11.794, de 8 de outubro de 2008, do Decreto $n \div 6.899$, de 15 de julho de 2009, e com as normas editadas pelo Conselho Nacional de Controle e Experimentaçăo Animal (CONCEA). Ante esta conformidade, o referido projeto foi avaliado e aprovado em 18/04/2017 pela COMISSÃO DE ÉTICA NO USO DE ANIMAIS do instituto de Cièncias Biomédicas da Universidade de Săo Paulo (CEUA-ICB/USP), outorgando esta licença de uso de animais com validade de 4 ano(s) a partir da data de aprovaçäo.

- Investigador Principal: Dr.(a.) Maria Regina D'Império Lima

- Departamento: Imunologia

- Membros da Equipe: isabella Cunha (Pós-graduando)

AD final do periodo outorgado por esta licença, o pesquisador responsável deverá encaminhar a esta comissåo, até o último dia de validade da atual proposta, relatório final de acordo com a Resolução Normativa CONCEA ne 30/2016. Diretriz Brasileira para o Cuidado e a Utilizaçăo de Animais em Atividades de Ensino ou de Pesquisa Cientifica (DBCA), conforme modelo constante no endereço eletrônico www.icb.usp.br/cevo. Havendo interesse na renovação do projeto, a solicitaçăo deverá ser protocolada pela Secretaria da CEUA-ICB/USP até o último dia de validade da atual proposta. Após esta data uma nova proposta deverá ser encaminhada.

\section{CERTIFICATE}

We hereby certify that the project entitled "Participotion of the $\mathbf{P 2 X 7}$ receptor in the differentiation and death of Th celis during the development of experimental malaria', protocol $n 945 / 2017$, which involves the production, maintenance and/or use of animals belonging to the phylum Chordata, subphylum Vertebrata lexcept human), for Scientific Research Purposes, is in accordance with the provisions of the Law $n^{2} 11.794$ passed on October $8^{7}, 2008$, Decree $n^{2} 6899$ passed on July $15^{t h}, 2009$, and the rules issued by the National Council for Control and Animal Experimentation (CONCEA). According to this legislation, the project was evaluated and approved on $4 / 18 / 2017$ by the ETHICS COMMITTEE ON ANIMAL. USE, Institute of Biomedical Sciences, University of Sao Paulo (CEUA-ICB/USP], and the license for animal use is valid for 4 year(s) from the date of approval.

- Principal Investigator: Dr.(a.) Maria Regina D'Império Lima

- Team members: Isabelia Cunho / Graduate Student.

At the end of the period granted by this license, the Principal Investigator must submit a final report of the project to this committee, according to the Rule $n^{2} 30$ and the Diretriz Brasileira para o Cuidado e a Utilização de Animais em Atividades de Ensino ou de Pesquisa Cientifica (DECA) issued by the CONCEA. If a renewal of the project is intended, the request must be submitted to the CEUA-KCB/USP secretary before the expiration of the current proposal. After this date, a new proposal must be prepared.

\begin{tabular}{|c|c|c|c|c|}
\hline Espécie/Species & Linhagem/Strain & Sexo/Gender & Idade-Peso/ Age-Weight & Total \\
\hline Mus musculis & 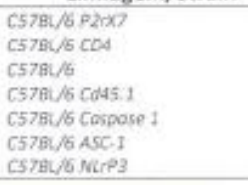 & $\begin{array}{l}\text { Fèmea/femaie } \\
\text { Fìmea/femaic } \\
\text { Fèmea/femaie } \\
\text { Fèmea/femaie } \\
\text { Fëmea/fermaie } \\
\text { Fìmea/femaic } \\
\text { Fèmea/femaie }\end{array}$ & $\begin{array}{l}6-8 \text { semano/weets } \\
6.8 \text { semanis/weeks } \\
6-8 \text { semano/weeks } \\
6-8 \text { semanis/weeks } \\
6-8 \text { semano/weeks } \\
6-8 \text { semano/weeks } \\
6.8 \text { semano/werks }\end{array}$ & $\begin{array}{c}150 \\
30 \\
400 \\
6 \\
16 \\
16 \\
16\end{array}$ \\
\hline
\end{tabular}

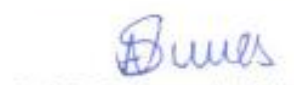

Prof. Dr. Anderson de Sá Nunes Coordenador CEUA-1CB/USP

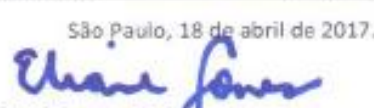

Eliane Aparecida Gomes de M. Qascimento Secretario CEUA-ICB/USP 
Dedico este trabalho aos meus pais, Nancy e Marco Pollo, que tanto me apoiaram e me deram suporte durante toda minha jornada; e à minha irmã, Rafaela, por todo o carinho $e$ compreensão. 


\section{AGRADECIMENTOS}

De todo o coração sou grata à Deus, ao meu anjo da guarda e aos meus guias espirituais, por nunca me permitirem desistir desta longa jornada.

Àqueles que representam minha base, meus pais, Nancy e Marco Pollo, , minha irmã, Rafaela e meu cunhado, João Paulo. Ao me dedicarem seu amor, carinho, compreensão, incentivo e todo apoio nessa fase que se encerra. À vocês minha mais sincera gratidão.

À minha orientadora, Dra. Maria Regina D' Império Lima, pela sua paciência comigo e por todas as vezes que me incentivou a aprender mais. Agradeço pelas oportunidades que me proporcionou, por abrir as portas do seu laboratório e me permitir trabalhar e aprender neste universo tão rico de conhecimento.

À pós doutoranda Érika Machado de Salles pela oportunidade de fazer parte do seu artigo, por todos os socorros em busca de conhecimento e paciência.

Ao técnico de laboratório Rogério Silva do Nascimento pela indicação para compor a equipe, confiança no meu potencial, suporte em todos os momentos difíceis e todas nossas conversas ao longo destes 2 anos.

Ao doutorando Renan pelos primeiros ensinamentos no laboratório, pelo carinho e todo o suporte.

À pós doutoranda Paula Carolina de Souza por todas nossas conversas, idas ao cinema e teatro e todo o suporte psicológico. Por todo o carinho e disponibilidade sempre, o meu eterno obrigada.

Ao professor José Maria Alvarez Mosig (Pepe) pelo incentivo, carinho e contribuição durante nossas reuniões de laboratório.

Às técnicas Áurea e Silvana por toda ajuda que sempre me deram.

Aos colegas de laboratório Beatriz, Paulo Cesar, Rafael, Raíssa, Maria, Caio, Débora, Gislane, Igor e Paulo pelos incentivos, socorro e amizade. 
Aos amigos Tábata e Marco Antonio pelos nossos finais de semana de estudo e dedicação no primeiro semestre de estágio.

À minha amiga Josiane Betim de Assis por toda a ajuda nas citometrias, e ensinamentos de metodologia. Pelo consolo em todos os momentos de desespero, pelo abraço amigo, meu mais sincero obrigada.

Ao meu amigo Caio Silveira pelo companheirismo no final desta jornada, e pelo incentivo em não desistir.

Aos meus queridos amigos da portaria e da limpeza, pelas conversas, risadas, amizade e carinho. À coordenadora do biotério Sandra Alexandre pela disponibilização de camundongos, por toda ajuda e conversas. À toda equipe do biotério pela manutenção e cuidados com os animais.

Ao professor Jean Pierre Schatzamnn Peron pela oportunidade que me proporcionou ingressar na pós graduação e estagiar no seu laboratório.

Aos Drs. Flavio Vieira Loures, Tarcio Braga e Maria Notomi Sato, por aceitarem compor a minha banca de qualificação e sugestões que contribuíram na realização deste projeto.

À Maria Eni, secretária da Pós-Graduação, por sempre acreditar no meu potencial, pela ajuda espiritual e pelo carinho.

À todos os amigos de norte à sul do país que de alguma forma me incentivaram a continuar e realizar este sonho.

Por fim, agradeço à CAPES e à FAPESP, que proprocionaram o auxílio financeiro para o desenvolvimento desse projeto. 
"O que vale na vida não é o ponto de partida e sim a caminhada.

Caminhando e semeando, no fim terás o que colher"

Cora Coralina 
Este trabalho foi desenvolvido no Laboratório de Imunologia das Doenças Infecciosas, Departamento de Imunologia do Instituto de Ciências Biomédicas Universidade de São Paulo, com o apoio financeiro do Programa de Excelência Acadêmica-Coordenação de Aperfeiçoamento de Pessoal de Nível Superior (PROEX-CAPES) e da Fundação de Amparo à Pesquisa do Estado de São Paulo (FAPESP - Projeto Temático 2015/20432-8). 


\section{RESUMO}

CUNHA, I. Participação do receptor P2X7 no controle das populações de células Tfh e B esplênicas e na proteção contra o Plasmodium yoelii. 2018. 69 f. Dissertação (Mestrado em Imunologia) - Instituto de Ciências Biomédicas, Universidade de São Paulo, São Paulo, 2018.

A imunidade à malária é de curta duração e os indivíduos curados são susceptíveis a reinfecções. Algumas evidências sugerem que a deficiência na produção de anticorpos específicos ao parasito possa explicar a dificuldade em se desenvolver uma resposta imune eficaz contra a malária. As células $B$ são selecionadas em um ambiente altamente regulado, denominado centro germinativo, localizado nos órgãos linfoides secundários. A interação entre as células T foliculares (Tfh) e células B do centro germinativo permite a produção de plasmócitos de vida longa que secretam anticorpos com alta afinidade pelo antígeno e a geração de células $B$ de memória. Estudos recentes mostraram que a sinalização do receptor P2X7 pelo ATP extracelular afeta a resposta das células T. Na infecção pelo Plasmodium chabaudi, o receptor P2X7 contribui para o controle do parasito favorecendo a produção de células Th1 produtoras de IFN-y em detrimento da população de células Tfh. Neste trabalho, buscamos avaliar a participação do receptor P2X7 na produção das células Tfh e células B do centro germinativo em camundongos infectados pelo Plasmodium yoelii $17 \mathrm{XNL}$. Este estudo justifica-se uma vez que a proteção contra $\circ P$. yoelli $17 X N L$ depende principalmente dos anticorpos, enquanto o IFN-y é essencial para 0 controle da infecção aguda pelo o $P$. chabaudi. Nossos resultados mostram que camundongos nocautes para 0 receptor P2X7 $\left(\mathrm{P} 2 \mathrm{X} 7^{-1}\right)$ apresentaram menores parasitemias que os camundongos C57BL/6 na fase aguda da infecção. Porém, o tempo decorrido até pico de parasitemia e o controle do parasito foram semelhantes em ambos os grupos. Observamos ainda uma anemia menos acentuada na ausência do receptor P2X7, mas este achado deve ser confirmado pois trata-se de um único experimento. Camundongos $\mathrm{P} 2 \mathrm{X}^{-1-}$ infectados apresentaram maior aumento no número de células $\mathrm{T} \mathrm{CD4}{ }^{+}$, células Tfh, células $\mathrm{B}$, células $\mathrm{B}$ do centro germinativo e plasmócitos no baço, em relação aos camundongos C57BL/6 infectados. Além disso, as frequências de células mortas nas populações de células $\mathrm{T} \mathrm{CD4}^{+}$e B eram menores na ausência do receptor P2X7. Entretanto, na fase aguda da infeção, os níveis séricos de anticorpos lgM e lgG2c específicos ao parasito eram semelhantes nos camundongos P2X7-/- e C57BL/6. Concluindo, este estudo mostra que o receptor P2X7 prejudica a expansão das populações de células Tfh e B do centro germinativo, assim como o controle da malária causada pelo $P$. yoelli $17 \mathrm{XNL}$. 


\begin{abstract}
CUNHA, I. Participation of the P2X7 receptor in the control of splenic Tfh and B cell populations and protection against Plasmodium yoelii. 2018. 69 f. Dissertation (Master in Immunology) - Institute of Biomedical Sciences, University of São Paulo, São Paulo, 2018.
\end{abstract}

Immunity to malaria is short-lived and cured individuals are susceptible to reinfections. Some evidence suggests that deficiency in the production of parasitespecific antibodies may explain the difficulty in developing an effective immune response against malaria. $B$ cells are selected in a highly regulated environment, named the germinal center, located in the secondary lymphoid organs. The interaction between follicular $T$ cells (Tfh) and germinal center B cells allows the production of long-lived plasma cells that secrete antibodies with high affinity for the antigen and generation of memory B cells. Recent studies have shown that P2X7 receptor signaling by extracellular ATP affects the $\mathrm{T}$ cell response. In Plasmodium chabaudi infection, the P2X7 receptor contributes to parasite control by favoring the production of Th1 cells secreting IFN-y to the detriment of the Tfh cell population. In this work, we aimed to evaluate the participation of the $\mathrm{P} 2 \mathrm{X} 7$ receptor in the production of Tfh cells and germinal center B cells in mice infected with Plasmodium yoelii $17 \mathrm{XNL}$. This study is justified since the protection against $P$. yoelli 17XNL depends mainly on antibodies, whereas IFN- $\gamma$ is essential for the control of acute $P$. chabaudi infection. Our results show that P2X7 knockout mice (P2X7 $7^{-/-}$) displayed lower parasitemias than the C57BL/6 mice in the acute phase of infection. However, the time elapsed until the peak of parasitemia and control of the parasite were similar in both groups. We also observed less marked anemia in the absence of the P2X7 receptor, but this finding must be confirmed because a single experiment was performed. Infected P2X7/- mice showed a greater increase in the number of $\mathrm{CD} 4^{+} \mathrm{T}$ cells, Tfh cells, B cells, germinal center B cells and plasma cells in the spleen, compared to infected C57BL/6 mice. In addition, the frequencies of dead cells in the populations of $\mathrm{CD}^{+} \mathrm{T}$ cells and $\mathrm{B}$ cells were lower in the absence of the P2X7 receptor. Nevertheless, in the acute phase of infection, serum levels of parasitespecific IgM and IgG2c antibodies were similar in P2X7-- and C57BL/6 mice. In conclusion, this study shows that the P2X7 receptor impairs the expansion of the Tfh cell and germ center $B$ cell populations, as well as the control of $P$. yoelli $17 \mathrm{XNL}$ malaria. 


\section{LISTA DE FIGURAS}

Figura 1 Ciclo de vida do Plasmodium... 21

Figura 2 Ação de anticorpos contra o merozoíto e o eritrócito infectado ............................................. 24

Figura 3 Sinalização Purinérgica na ativação das Célula T .............................................................. 29

Figura 4 Monitoramento da parasitemia e hemoglobina em camundongos C57BL/6 e P2X7infectados pelo $P$. yoelii.

Erro! Indicador não definido.

Figura 5 Estratégia de análise usada para definir subpopulações de células $C D 4^{+}$e CD19+ no baço de camundongos $\mathrm{C} 57 \mathrm{BL} / 6$ e P2X7-/ infectados pelo $P$. yoelii.

Erro! Indicador não definido.

Figura 6 Estratégia de análise usada para definir subpopulações de células CD4+ e CD19+ no baço de camundongos C57BL/6 e P2X7-/ infectados pelo $P$. yoelii.

Erro! Indicador não definido.

Figura 7 Frequência e número absoluto de células CD4+LD+ no baço de camundongos C57BL/6 e P2X7- infectados pelo $P$. yoelii.

Erro! Indicador não definido.

Figura 8 Frequência e número absoluto de células CD19+LD+ no baço de camundongos C57BL/6 e P2X7- infectados pelo $P$. yoelii.

Erro! Indicador não definido.

Figura 9 Análise das populações de células ICOS+BCL6+; CXCR5+BCL6+ e PD-1+BCL6+ no baço de camundongos C57BL/6 e P2X7-/ no dia 14 de infecção pelo $P$. yoelii.... Erro! Indicador não definido. Figura 10 Frequência e número absoluto de células ICOS+BCL6+; CXCR5+BCL6+ e PD-1+BCL6+ no baço de camundongos $\mathrm{C} 57 \mathrm{BL} / 6$ e $\mathrm{P} 2 \times 7^{-/}$no dia 14 de infecção pelo $P$. yoeliErro! Indicador não definido.

Figura 11 Cinética da população de células PD-1 high CXCR5 high no baço de camundongos C57BL/6 e P2X7-/ infectados pelo $P$. yoelii.

Erro! Indicador não definido.

Figura 12 Frequência e número absoluto de células Fas ${ }^{+} \mathrm{GL} 7{ }^{+} \mathrm{CD} 19^{+}$no baço de camundongos C57BL/6 e P2X7-- infectados pelo P. yoelii

Erro! Indicador não definido.

Figura 13 Frequência e número absoluto de células $\mathrm{CD} 138^{+} \mathrm{CD} 19^{+}$no baço de camundongos C57BL/6 e P2X7/- infectados pelo $P$. yoelii ...

Erro! Indicador não definido.

Figura 14 Anticorpos IgM e IgG2c específicos no soro de camundongos C57BL/6 e P2X7-/ infectados pelo $P$. yoelii ......

Erro! Indicador não definido. 


\section{LISTA DE ABREVIATURAS, SIGLAS E SÍMBOLOS}

ADP - Adenosina difosfato

AMP - Adenosina monofosfato

APC - Célula Apresentadora de Antígeno

APC - Aloficocianina

APC-Cy7 - Aloficocianina-Cy7

ATP - Adenosina trifosfato

Bcl6 - Proteína 6 do linfoma de células B

Blimp-1 - Proteína de maturação de linfócitos $B$

BSA - Albumina sérica bovina

CONCEA - Conselho Nacional de Controle de Experimentação Animal

CSP - Proteína circunsporozoíta

CXCR5 - Receptor de quimiocina C-X-C tipo 5

DAMP - Via molecular associada ao dano

d.p.i. - dias pós infecção

ELISA - do inglês, "enzyme-linked immunosorbent assay"

EP - Eritrócitos parasitados

GPI - glicosil-fosfatidil-inositol

$\mathrm{Hb}$ - Hemoglobina

i.p. - intraperitoneal

ICOS - Coestimulador de células T induzível

IFN - Interferon

Ig - Imunoglobulina

IL- Interleucina

ICB/USP - Instituto de Ciências Biomédicas da Universidade de São Paulo.

iRBC - Eritrócitos parasitados

LD - Live/Dead

LT - Linfócito T

mAb - Anticorpo monoclonal

MHC - Complexo principal de Histocompatibilidade

NK - do inglês, Natural Killer cell

OMS - Organização Mundial de Saúde 
OPAS - Organização Pan-Americana da Saúde

P. - Plasmodium

PBS - Salina tamponada com fosfato

PD-1 - Proteína de morte celular prgramada

PE - Ficoeritrina (Phycoerythrin)

PEcy-7 - Ficoeritrina-Cy7

PerCp - Complexo proteína clorofila peridinina

RPMI - Meio McCoy de cultura modificada

SBF - Soro bovino fetal

STAT - Transdutores de sinal e ativadores de transcrição

TCR - Receptor de célula T

Th - Célula T auxiliar

Tfh - Células T auxiliares do folículo

TGF- $\beta$ - Fator $\beta$ de transformação de crescimento

TLR - Receptor do tipo Toll

TMB - Tetrametilbenzidina

TNF $\alpha$ - Fator de Necrose Tumoral $\alpha$

WHO - do inglês, World Health Organization

$\alpha-$ alfa

$\beta$ - beta

$\gamma$-gama

$\delta$ - delta

$\mu-$ micro

-/- - nocaute 


\section{SUMÁRIO}

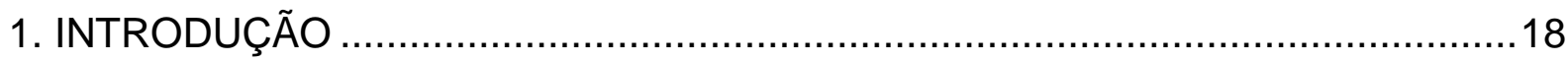

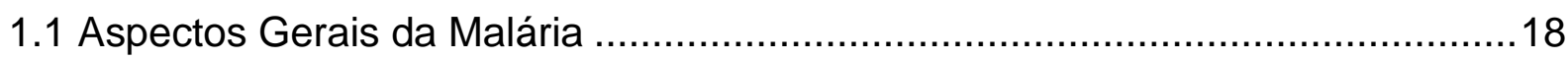

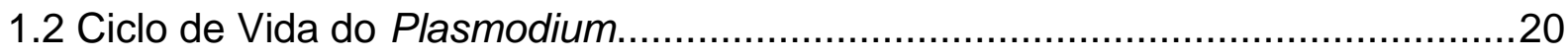

1.3 Resposta Imune ao Plasmodium no Homem ..................................................22

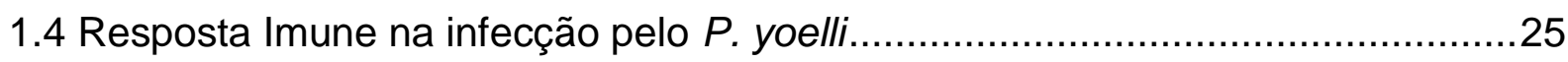

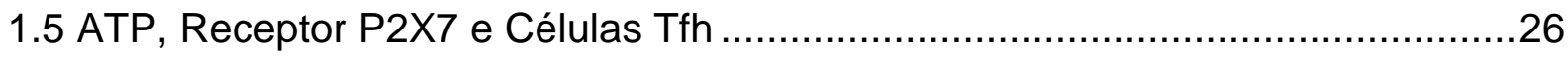

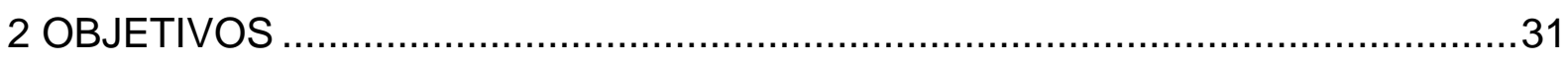

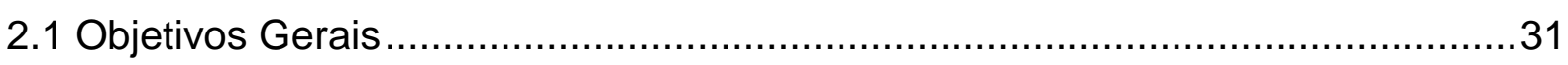

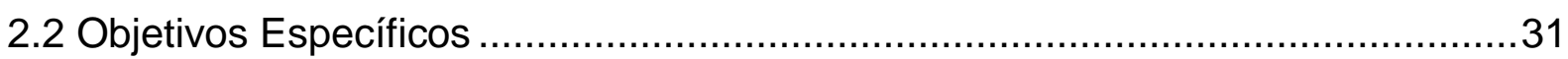

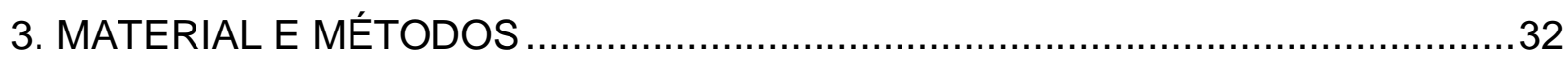

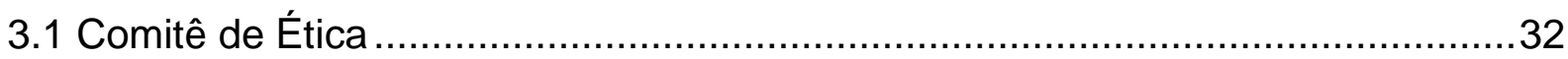

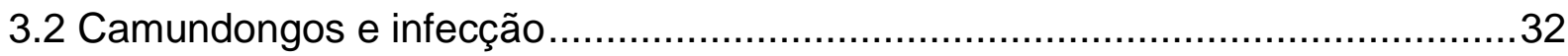

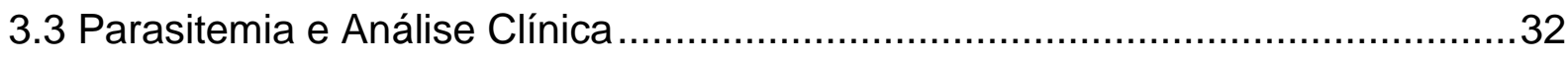

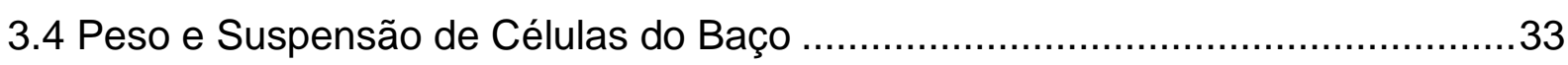

3.5 Análise Fenotípica das Células por Citometria de Fluxo ....................................33

3.6 Purificação e Sincronização dos Reticulócitos Parasitados .................................34

3.7 Preparação do Extrato do Antígeno do $P$. yoelii 17XNL .....................................35

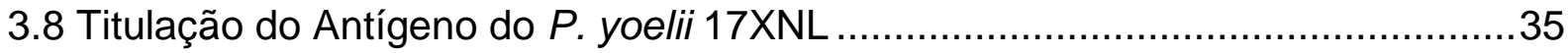

3.9 Detecção por ELISA dos Anticorpos Específicos ao Parasito no Soro …….........35

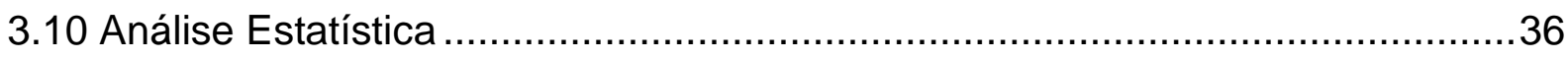

4 RESULTADOS ........................................................... Indicador não definido.

4.1 A ausência do receptor P2X7 contribui para a proteção contra o $P$. yoelii 17XNL

Erro! Indicador não definido.

4.2 A ausência do receptor $P 2 X 7$ favorece a expansão das populações de células $T$ $\mathrm{CD}^{+}$e CD19+ esplênicas durante a infecção pelo $P$. yoelii 17XNLErro! Indicador não definido.

4.3 O receptor $\mathrm{P} 2 \mathrm{X} 7$ favorece a morte de células $\mathrm{CD} 4^{+}$e $\mathrm{CD} 19^{+}$durante a infecção pelo $P$. yoelii $17 \mathrm{XNL}$ Erro! Indicador não definido.

4.4 A ausência do receptor P2X7 favorece a produção de células Tfh durante a infecção pelo $P$. yoelii $17 \mathrm{XNL}$

Erro! Indicador não definido.

4.5 A ausência do receptor $\mathrm{P} 2 \mathrm{X} 7$ favorece a produção de células $\mathrm{B}$ do centro germinativo durante a infecção pelo $P$. yoelii 17XNL ...Erro! Indicador não definido. 
4.6 A ausência do receptor $\mathrm{P} 2 \mathrm{X} 7$ favorece a produção de plasmócitos durante a infecção pelo $P$. yoelii 17XNL.....................................Erro! Indicador não definido. 4.7 A ausência do receptor P2X7 não altera os níveis séricos de anticorpos IgM e IgG2c específicos na fase aguda da infecção pelo $P$. yoelii 17XNL.Erro! Indicador não definido.

5 DISCUSSÃO ................................................................. Indicador não definido.

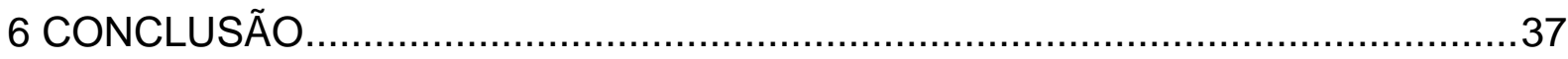



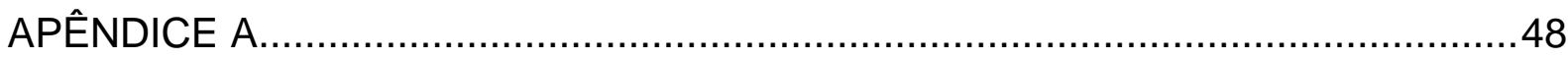

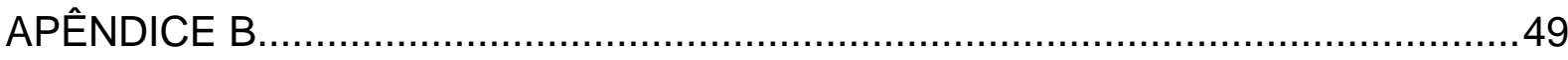




\section{INTRODUÇÃO}

\subsection{Aspectos Gerais da Malária}

A malária é uma doença infecciosa endêmica em regiões tropicais e subtropicais do globo e resulta em alta morbidade e mortalidade. Segundo a Organização Mundial de Saúde (OMS), no ano de 2016 houve aproximadamente 220 milhões de casos e 445 mil mortes decorrentes da malária no mundo, sendo que mais de $90 \%$ dos casos pertenciam à Região Africana. Este relatório foi baseado em 91 países e em áreas de transmissão contínua (WHO, 2017).

No Brasil, a maioria dos casos de malária está na região Amazônica, que contempla os estados do Acre, Amapá, Amazonas, Maranhão, Mato Grosso, Pará, Rondônia, Roraima e Tocantins. Embora nas demais regiões o número de casos se apresente com menor incidência, observa-se um nível maior de letalidade quando comparado à região Amazônica. Sendo assim, é necessário o controle da doença nestas regiões diante do fluxo migratório provenientes de regiões suscetíveis e da alta letalidade, que resulta do diagnóstico tardio e manejo clínico inadequado. (Ministério da Saúde, 2017). A Organização Pan-Americana da Saúde em seu último relatório constatou que houve um aumento de $48 \%$ no número de casos de malária entre os anos de 2016 e 2017 na Região Amazônica, chegando a aproximadamente 175 mil ocorrências (OPAS, 2018).

Os primeiros relatos descritos desta doença advém de documentos chineses datados de quase três mil anos a.C.. Em 440 a.C., Hipócrates descreveu características sintomáticas como a febre malárica e a esplenomegalia em indivíduos residentes em locais pantanosos (Cox, 2010). Porém, somente há pouco mais de cem anos, houve a descoberta que seu transmissor era um protozoário. Em 1880, Alphonse Laveran relatou a presença de gametócitos masculinos no sangue de um paciente febril. Laveran mostrou que a malária era decorrente de um parasito que invadia as células vermelhas do sangue do hospedeiro e multiplicava em seu interior. O parasito foi inicialmente denominado Oscilliaria malariae e posteriormente Plasmodium. Somente em 1898, o vetor e o ciclo de transmissão do parasito na fase sexuada foram descobertos por um conjunto de pesquisadores, dentre eles Ronald Ross, Giovanni Battista Grassi, Amico Bignami, Giuseppe Bastianelli, Angelo Celli, Camillo Golgi e Ettore Marchiafava (Doolan et al, 2009; Tan, Ahana, 2009; Cox, 2010). 
Sua transmissão ocorre pela picada do mosquito fêmea do gênero Anopheles infectado pelo protozoário do gênero Plasmodium. Em humanos, cinco espécies de protozoários podem causar a malária. A transmissão do parasito das espécies Plasmodium falciparum, Plasmodium vivax, Plasmodium malariae e Plasmodium ovale ocorre de um hospedeiro humano para outro por meio da picada do mosquito. Já no caso do Plasmodium knowlesi a infecção se faz de forma zoonótica (Cox-Singh et al., 2008). Esta espécie do parasito costumava estar associada a casos de malária em macacos, porém atualmente tem sido descrita a infecção humana (Daneshvar et al., 2009).

No Brasil, três espécies estão associadas à malária humana, $P$. vivax, $P$. falciparum e $P$. malariae, sendo que há maior prevalência de infecções com $\circ P$. vivax (Ministério da Saúde, Brasil, 2015 Boletim Epidemiológico). Há também a presença de formas mistas onde o indivíduo é infectado por mais de uma espécie do protozoário (WHO, 2017: World Malaria Report 2017).

Em vista da escassez de conhecimento acerca da biologia do Plasmodium e sua ação no hospedeiro humano, vem-se utilizando modelos murinos como fundamento para o estudo in vivo do desenvolvimento da doença. Estes modelos experimentais têm contribuído para caracterizar a resposta do hospedeiro associada ao combate do parasito nos estágios pré-eritrocíticos e eritrocíticos (Long et al., 1994). O uso de animais favorece o estudo do papel da resposta imune celular e humoral em inúmeras infecções devido à similaridade da respostas em humanos. Há várias espécies de Plasmodium que infectam o camundongo e causam patologias com características similares às observadas na infecção humana. O estudo da malária vem utilizando quatro espécies murinas do Plasmodium: Plasmodium berghei, Plasmodium vinckei; Plasmodium chabaudi e Plasmodium yoelii (Carlton et al., 2002). Estes parasitos foram isolados na África Central sub-Saariana entre os anos de 1940 e 1960. Os hospedeiros naturais destas espécies são os roedores do gênero Grammomyssurdaster para o $P$. berghei e do gênero Thamnomysrutilans para as demais espécies (Stephens et al., 2012). O P. chabaudi e o P. vinckei infectam eritrócitos maduros e se desenvolvem de maneira sincrônica causando o rompimento quase que simultâneo destas células, enquanto $\circ P$. yoelii e $\circ P$. berghei infectam reticulócitos e são assincrônicos (Bagnaresi et al., 2009; Stephens et al., 2012). O P. yoelii é capaz de infectar eritrócitos quando há limitação de reticulócitos (Cernetich-Ott et al., 2012). 


\subsection{Ciclo de Vida do Plasmodium}

O ciclo de vida do parasito apresenta duas etapas; a fase sexuada ocorre no vetor que é o mosquito fêmea do gênero Anopheles e a fase assexuada ocorre no hospedeiro vertebrado. Por intermédio da picada do mosquito infectado, os esporozoítos são liberados na pele do hospedeiro (Figura 1). Em seguida, adentram na circulação sanguínea e a partir daí migram para o fígado (fase pré-eritrocítica), onde irão invadir os hepatócitos. Esta etapa é caracterizada como um estágio silencioso, onde não há sintomatologia clínica.

A adesão dos esporozoítos aos hepatócitos se faz por intermédio da proteína circunsporozoíta (CSP), que é a principal proteína de superfície dos esporozoítos (Ménard, 2000), e vem sendo utilizada como um dos alvos antigênicos para o desenvolvimento de vacinas. A invasão do hepatócito leva à formação de um compartimento, o vacúolo parasitóforo, que envolve o esporozoíto (Silvie et al., 2008). O parasito se desenvolve dentro do hepatócito em um processo celular conhecido como esquizogonia. Trata-se de um processo endomitótico caracterizado pelo aumento na massa celular com replicação concomitante de DNA e organelas, mas sem citocinese (Dankwa et al., 2016). O resultado da esquizogonia é a produção de merozoítos, que ao serem liberados na corrente sanguínea ficam envoltos em uma estrutura denominada merossomo (Sturm et al.,2006) - estrutura pertencente ao próprio hepatócito. A estrutura do merossomo protege os merozoítos de serem reconhecidos por fagócitos residentes, como por exemplo, as células de Küpffer (Sturm et al., 2006). Os merozoítos liberados passam a infectar os eritrócitos, dando início ao ciclo eritrocítico (Silvie et al., 2008; Aly et al., 2009). 
Figura 1 Ciclo de vida do Plasmodium

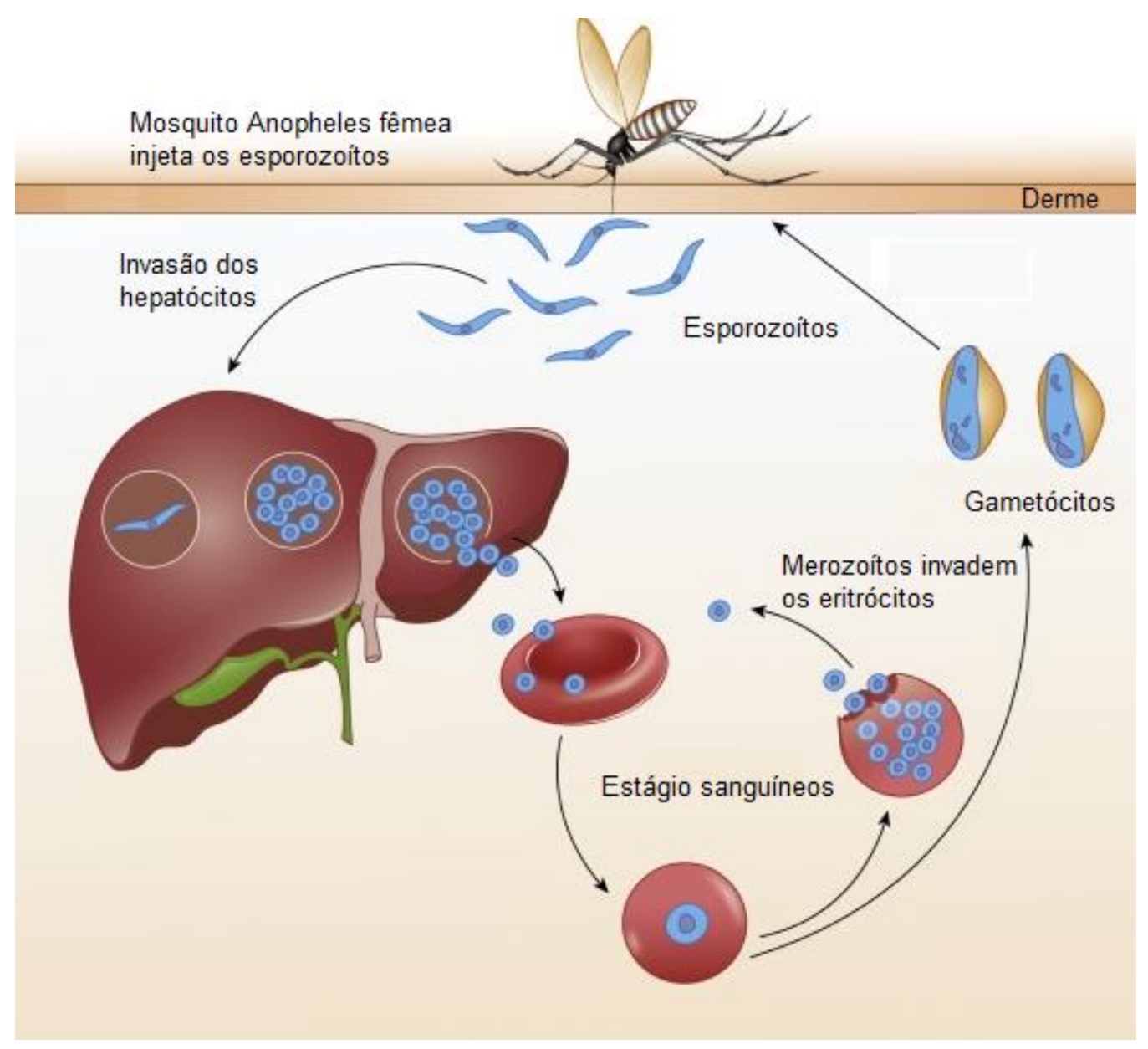

Fonte: Adaptado de Teo et al., 2016

Dentro dos eritrócitos, os merozoítos se desenvolvem em trofozoítos jovens e posteriormente em trofozoítos maduros que se multiplicam e maturam até a formação de esquizontes que irão se replicar entre 16-32 merozoítos filhos (Cowman, Crabb, 2006). Após a etapa de maturação, há o rompimento dos eritrócitos infectados com a liberação dos merozoítos na corrente sanguínea, os quais irão infectar novos eritrócitos, reiniciando o ciclo de infecção eritrocítica (Good, Doolan, 2010). Os ciclos de rompimento e desenvolvimento acontecem em intervalos de tempo definidos, que variam de acordo com a espécie do parasita. Por exemplo, o ciclo eritrocítico é repetido a cada 48 horas nas infecções com $P$. vivax e $P$. falciparum (Crutcher, Hoffman, 1996) e a cada 72 horas na infecção com $P$. malariae. A escassez de nutrientes e o estresse gerado pelo microambiente, como a alta parasitemia, levam os merozoítos a se diferenciarem em gametócitos 
masculinos e femininos (Cowman et al., 2016). A continuidade do ciclo sexual no mosquito ocorre mediante a ingestão do sangue contendo os gametócitos.

Os sinais e sintomas clínicos característicos da malária são febre elevada, calafrios, dor de cabeça, sudorese profunda, náuseas e dores musculares (Dostert et al., 2009). Alguns indivíduos podem evoluir para as formas graves da doença como a síndrome respiratória, anemia intensa, acidose metabólica, malária cerebral e choque séptico (Bartoloni, Zammarchi, 2012; Cowman et al., 2016).

\subsection{Resposta Imune ao Plasmodium no Homem}

O sistema imune é capaz de reconhecer produtos derivados do parasito como também reconhecer o próprio eritrócito parasitado através dos receptores de reconhecimento de padrões (PRRs). Dois exemplos de produtos imunogênicos gerados pelo $P$. falciparum e reconhecidos pelos PRRs durante a infecção são as âncoras de glicosil-fosfatidil-inusitol (GPI) (Schofield, Hackett, 1993) e a hemozoína (Coban et al., 2005). Trabalhos in vitro utilizando monócitos humanos e macrófagos murinos mostraram que as âncoras de GPI induzem a ativação de receptores do tipo Toll (TLR) 1/TLR2 TLR2/TLR6 e TLR4 (Krishnegowda et al., 2005), assim como a produção de citocinas pró-inflamatórias como TNFa e IL-1 (Schofield, Hackett, 1993). A hemozoína é um cristal formado dentro do vacúolo alimentar do Plasmodium pelo processo de degradação da hemoglobina (Francis et al., 1997). Experimentos in vivo e in vitro utilizando hemozoína sintética e purificada de cultura de $P$. falciparum demonstraram que as células dendríticas de camundongos são capazes de reconhecer este cristal através do TLR9 (Coban et al., 2005).

A resposta imune celular e humoral é capaz de reconhecer antígenos do merozoíto. Estudos em humanos infectados pelo $P$. falciparum residentes em área endêmica demonstraram que a produção de IFN-ץ pelas células T CD4 ${ }^{+}$em resposta à antígenos do merozoíto está associada à proteção contra a infecção (Pombo et al., 2002; Moormann et al., 2013). Isto pode ser visto em um estudo envolvendo células mononucleares do sangue humano de crianças estimuladas in vitro durante 5 dias com eritrócitos infectados pelo $P$. falciparum, que resultou na produção de altos níveis de IFN-y e TNFa, indicando uma polarização para o perfil de resposta Th1. Além disso, quando o sangue de crianças residentes de área endêmica infectadas pelo $P$. falciparum foram analisadas, durante os primeiros dias de infecção, também apresentaram maior produção de células Th1 secretoras de 
IFN-y, assim como a produção de anticorpos de vida curta (Obeng-Adjei et al., 2015). No entanto, o desenvolvimento de uma resposta imune eficaz contra $0 P$. falciparum é relativamente lento, Isto é, indivíduos que habitam zonas endêmicas necessitam de repetidas exposições ao parasito para lhes conferir imunidade clínica não estéril, que este se caracteriza por baixos níveis de parasitemia na ausência de sintomas (Baird, 1995; Marsh e Kinyanjui, 2006; Tran et al., 2013).

Os anticorpos apresentam grande importância na imunidade contra a malária. O papel protetor dos anticorpos foi demonstrado em estudos envolvendo a transferência passiva de lgG de adultos imunes para indivíduos acometidos pela malária grave que, após o tratamento, foram capazes de controlar a parasitemia e melhoraram os sinais de febre (Cohen et al., 1961). Esses estudos sugeriram que a atuação destes anticorpos eram contra esquizontes maduros ou merozoítos extracelulares. A participação dos anticorpos que agem contra antígenos do merozoíto é importantes no controle da infecção pelo $P$. falciparum (Egan,.et al., 1996; Taylor et al., 1998; Braga et al., 2002; Metzger et al., 2003; Polley et al., 2006). Este papel foi demonstrado através de estudos em humanos e in vitro utilizando o soro de pacientes. Os anticorpos contra os antígenos do merozoíto apresentam inúmeras ações como neutralização, opsonização e o bloqueio da citoaderência de hemácias parasitadas no endotélio vascular (Khusmith et al., 1982; Khusmith et al., 1983; Bouharoun-Tayoun et al., 1990; Celada et al., 1982; Beeson et al., 2004; Beeson et al., 2013; Hill et al., 2013, Tran et al., 2012 , Chiu et al., 2015. Hansen et al., 2017) (Figura 2).

As subclasses de anticorpos lgG1 e lgG3 são as mais predominantes na resposta contra antígenos do merozoíto do $P$. falciparum (Taylor et al., 1995; Issa et al., 2008). Estes anticorpos são eficazes na fixação do complemento (Boyle et al., 2017) e apresentam alta afinidade pelos receptores Fc resultando na ativação de fagócitos (Bredius et al., 1994; Stubbs et al., 2011). Um estudo envolvendo crianças infectadas pelo $P$. falciparum demonstrou que os principais subtipos produzidos no soro foram os isótipos IgG1 e IgG3 contra os antígenos do merozoíto MSP1-19 (região C-terminal de 19-kDa da proteína de superfície do merozoíto 1), MSP2 (proteína de superfície do merozoíto 2) e AMA-1 (antígeno apical de membrana 1), entretanto os resultados demonstraram pouca reatividade dos isotipos IgG2 e IgG4 (Stanisic et al., 2009). 
Figura 2 Ação de anticorpos contra o merozoíto e o eritrócito infectado

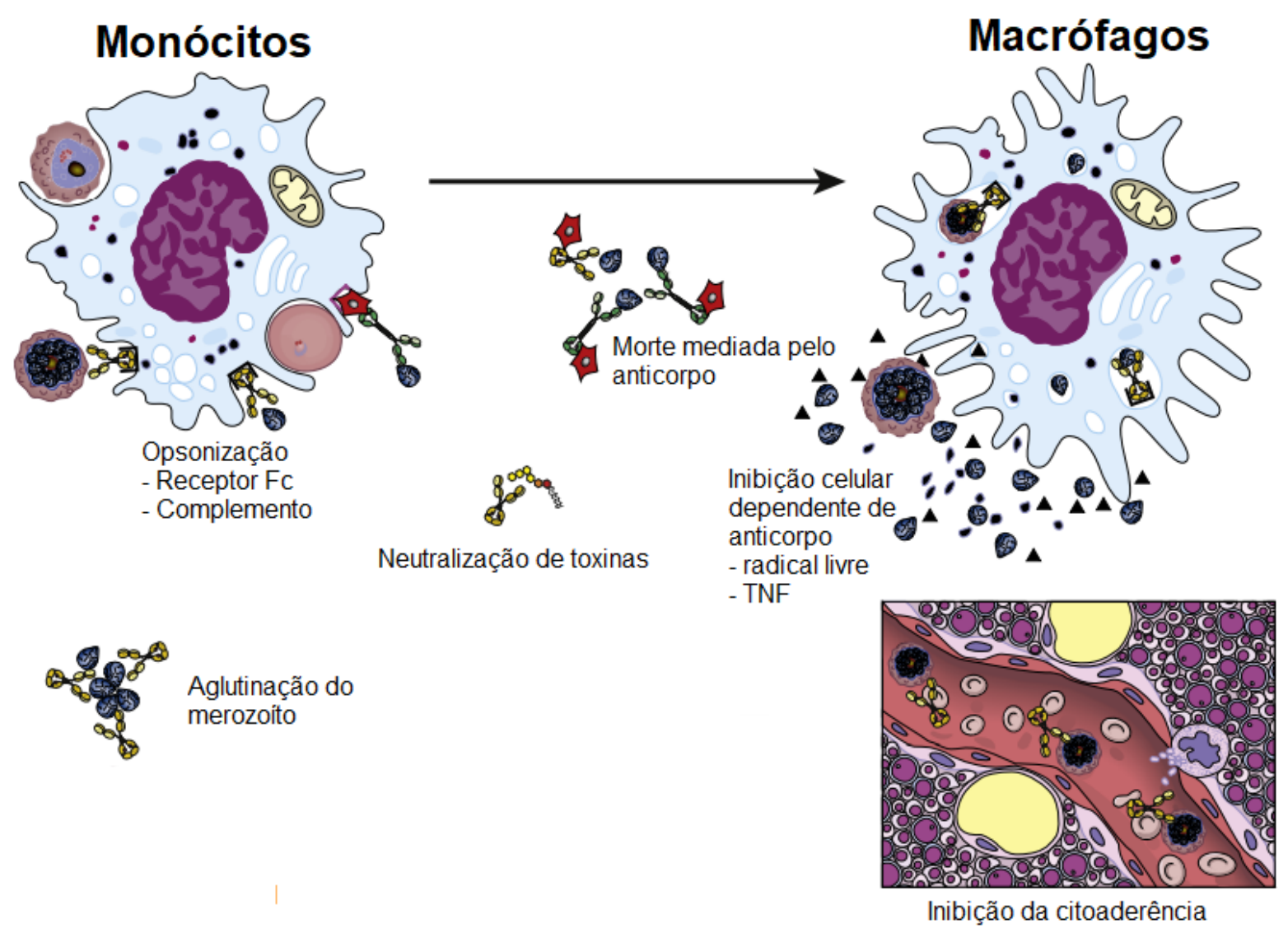

Fonte: Adaptado de Teo et al., 2016

As células T foliculares ${ }^{1}$ (Thㅡ) são um subtipo de célula T CD4+ que auxiliam na produção de anticorpos de alta afinidade, atuando na formação do centro germinativo (Crotty, 2011). A fim de esclarecer o papel destas células, foi realizado um estudo em crianças infectadas pelo $P$. falciparum em que as células Tfh e Th1 do sangue periférico formam cultivadas com SEB (enterotoxina estafilocócica do tipo B), um superantígeno que mimetiza a interação entre as células T antígeno-específicas

${ }^{1}$ As células Tfh foram identificadas dentro do centro germinativo, local onde ocorre sua interação com as células $B$, e a partir daí dão suporte para a resposta imune humoral, induzindo a produção de anticorpos de alta afinidade e de vida longa e células B de memória (Breitfeld et al., 2000). Características determinantes desta população são a alta expressão do fator de transcrição proteína 6 do linfoma de células B (Bcl-6), da proteína de morte celular programada (PD1), do coestimulador de células T induzível (ICOS) e do receptor de quimiocina C-X-C tipo 5 (CXCR5), além da secreção de IL-21 e da baixa expressão do receptor de quimiocina C-C tipo 7 (CCR7) (Tangye et al., 2013). O receptor de quimiocina CXCR5 atua na migração para dentro do folículo linfoide das células Tfh, que cooperam com as células B na formação do centro germinativo (Haynes et al., 2007). A participação das citocinas IL-21 (ação autócrina) e IL-6 está associada à sinalização dos ativadores de transdução de sinais de transcrição (STAT) STAT3/STAT1 e do fator de transcrição Bcl6, que resultam na diferenciação das células T CD4+ para o perfil Tfh (Nurieva et al., 2008). 
e células B apresentadoras de antígeno. Após 12 dias de co-cultura, as células Tfh induziram maior produção de anticorpos IgG quando comparadas às células Th1 (Obeng-Adjei et al., 2015). Entretanto, este estudo foi realizado apenas na fase aguda, não havendo publicação acerca das funções das células Tfh no sangue de humanos infectados pelo $P$. falciparum numa fase mais tardia da infecção. Por outro lado, durante a infecção pelo $P$. vivax, os indivíduos apresentaram aumento na produção de células Tfh circulantes e anticorpos IgM, IgG1, IgG3 e lgG4 já na fase aguda da doença (Figueiredo et al., 2017). Este mesmo estudo ainda demonstrou que estes pacientes apresentaram aumento na produção de citocinas IFN- $\gamma$, IL-21, IL-6 e IL-10, o que conferiu o controle da infecção pelo P.vivax. A IL-21 auxilia na troca de classe de anticorpos e na produção de plasmócitos (Ettinger et al., 2005; Morita et al., 2011), a IL-6 é responsável pela diferenciação das células Tfh (Choi et al., 2013), e a IL-10 induz as células B ativadas a secretar imunoglobulinas (Rousset et al., 1992).

\subsection{Resposta Imune na infecção pelo $P$. yoelli}

Tendo como intuito ampliar o conhecimento adquirido através dos estudos em humanos, modelos murinos infectados pelo Plasmodium vêm sendo utilizados como estratégia de pesquisa. O P. yoelii mimetiza características imunogênicas e patogênicas da infecção pelo P. falciparum (Li et al., 2011; Guthmiller et al., 2017), tornando-se um bom objeto de estudos para resposta imune humoral frente à infecção. A infecção pelo $P$. yoelii apresenta características que diferem da infecção pelo $P$. chabaudi, como a preferência em infectar exclusivamente reticulócitos e apresentar um ciclo assincrônico de infecção (Bagnaresi et al., 2009; Stephens et al., 2012; Raja et al., 2016).

Assim como na infecção pelo $P$. falciparum, o controle do parasito durante a fase aguda de infecção pelo $P$. yoelii é decorrente da ação de macrófagos (Couper et al., 2008), de citocinas como IFN-y e TNFa produzidas pelas células natural killer (NK), LTyס (Choudhury et al., 2000) e células Th1. As células dendríticas atuam na fase aguda da infecção pelo $P$. yoelii, através da produção de citocinas próinflamatórias IL-12 e TNF-a, aumentando a ativação de células Th1 produtoras de IFN-y (Ueffing et al, 2017). Entretanto à medida que a infecção progride estas células passam a produzir IL-10 (Perry et al., 2005), e o aumento na produção desta citocina na fase tardia da infecção pelo $P$. yoelii, favorece a supressão das células 
Th1 e limita a produção de IFN-y (Gutmuller et al., 2017). Omer e colaboradores (2003) demonstraram que camundongos infectados com o $P$. yoelii apresentavam níveis imperceptíveis de produção TGF- $\beta$ e IL-10 na fase aguda da infecção, entretanto numa fase mais tardia seus níveis são altos contribuindo no controle do parasito (Omer et al., 2003). As células T CD4+ produtoras de IL-10 que auxiliam no controle do $P$. yoelii não são as células $T$ reguladoras convencionais, e sim as células Tr1 (Couper et al., 2008). Estudos mais recentes associam a IL-10 à imunidade humoral, uma vez que favorece as reações de células $B$ do centro germinativo e a troca de isotipos de anticorpos (Gutmuller et al., 2017).

A IL-21 mostrou-se importante no controle da infecção pelo $P$. yoelii, uma vez que camundongos nocautes para IL-21 ou o receptor da IL-21 não conseguiram resolver a fase crônica da infecção, resultando em alta parasitemia sustentada. Além disso, havendo uma reinfecção, estes camundongos não estão imunes ao parasito, visto que não há produção de células B de memória nem anticorpos lgG (PérezMazliah et al., 2015). Outra citocina importante no controle tardio da infecção pelo $P$. yoelii é a citocina IL-6, que favorece o desenvolvimento de respostas imunes humorais, a partir da segunda semana de infecção, uma vez que aumenta a produção de $\operatorname{lgM}$ e $\operatorname{lgG}$ específica ao parasito, regulando positivamente a expressão de ICOS pelas células Tfh e o desenvolvimento de células $B$ do centro germinativo (Sebina et al, 2017). As células Tfh vêm se mostrando importantes na fase tardia da infecção pelo $P$. yoelii, uma vez que favorecem a produção de células $B$ do centro germinativo, células B de memória (James et al., 2018) e plasmócitos produtores de anticorpos de alta afinidade (Butler et al., 2011; Zander et al., 2015; Sebina et al., 2016).

\subsection{ATP, Receptor P2X7 e Células Tfh}

O sistema imune reconhece produtos endógenos liberados em condições de dano celular ou injúria tecidual (Seong, Matzinger, 2004). A adenosina trifosfato (ATP) é um nucleotídeo importante como fonte de energia, presente em altas concentrações no meio intracelular, entretanto ao ser liberado para o meio extracelular, torna-se um importante mediador inflamatório atuando como uma molécula associada ao dano celular (DAMP). (Di Virgilio et al., 2003, 2009). Eritrócitos humanos infectados in vitro com o $P$. falciparum obtiveram níveis de ATP intracelular aumentado, e a hemólise resultante da infecção levou a abertura 
de canais de membrana, aumentando a liberação e concentração do ATP no meio extracelular e a ativação de receptores purinérgicos (Akkaya et al., 2008).

O ATP pode ser liberado para o meio extracelular através de exocitose, como por exemplo por canais denominado panexina-1 presente na membrana celular de linfócitos e eritrócitos (Locovei et al., 2006), assim como em condições de trauma e morte celular. Normalmente, o ATP está presente em altos níveis no compartimento citoplasmático, em concentrações que variam entre 1 a $10 \mathrm{mM}$ (Bours et al., 2006). Em contrapartida, no espaço extracelular, em condições fisiológicas, o ATP apresenta concentrações bem mais baixas que variam entre 1-10 nM (Coade, Pearson, 1989).

Sua liberação pode ser decorrente de condições patogênicas e não patogênicas, podendo resultar numa ampla gama de processos biológicos como a atividade quimiotática, ativação de diferentes células do sistema imune e liberação de mediadores inflamatórios (Di Virgílio et al., 2001). Em condições de grande injúria tecidual, o ATP atua como um mediador inflamatório, representando uma importante função na resposta imune, ao atuar nas células inflamatórias resultando em sua migração, proliferação, diferenciação celular e resposta efetora (Di Virgílio et al., 2001,2003 , 2009). Atua como sinal "find-me" e atrai fagócitos para o foco inflamatório, ativa plaquetas e estimula a óxido nítrico-sintase endotelial (eNOS) (Chekeni et al., 2010). Uma vez no espaço extracelular é degradado por ectonucleotidases e convertido em moléculas de ADP, AMP e adenosina (Robson et al., 2006).

A descoberta por Burnstock, em 1972, da existência de uma via de sinalização purinérgica permitiu a ampliação das ações biológicas do ATP. Em 1978, formalizou-se o reconhecimento de 2 famílias de receptores de membrana celular capazes de se ligar ao ATP e seus subprodutos: os receptores P1 (reconhecem a adenosina) e os receptores P2 (reconhecem nucleotídeos) (Burnstock 1972, 1978). Os receptores P2 são classificados em duas famílias, a família do P2X (receptor de canal iônico) e a família do P2Y (receptor acoplado à proteína G) (Verkhratsky et al., 2009). A família P2X inclui sete receptores (P2X1-P2X7) (Burnstock, 2007) que são responsáveis pela abertura de canais iônicos - seletivos para cátions monovalentes e divalentes como $\mathrm{Na}^{+}, \mathrm{K}^{+}$e $\mathrm{Ca}^{2+}$ - ativados em resposta ao reconhecimento do ATP extracelular (North, 2002). Os receptores P2X estão presentes em muitas células do sistema imune, tais como macrófagos, monócitos, neutrófilos, mastócitos, células 
dendríticas, linfócitos T e células NK. A família de receptores P2X desempenha um papel central na inflamação, em especial o receptor P2X7, expresso em quase todas as células do sistema imune (Adinolfi et al., 2018). Este receptor ao ser ativado na superfície celular, é capaz de ativar inflamassoma (Ferrari et al., 2006), participa na secreção de citocinas e quimiocinas (Kurashima et al., 2012), ativação e diferenciação de linfocitos $T$, ativação de fatores de transcrição (Amoroso et al., 2012) e morte celular (Di Virgilio et al.,1989).

$O$ receptor $\mathrm{P} 2 \mathrm{X} 7$ atua na inflamação e na resposta imune. A sinalização pelo receptor P2X7 induz a célula a produzir citocinas pró-inflamatórias como IL-6 em mastócitos (Kurashima et al., 2012), TNFa em células dendríticas (Ferrari et al., 2000); citocinas anti-inflamatórias como IL-10 e TGF- $\beta$ (Chessell et al., 2005; Monção-Ribeiro et al., 2014; Bianchi et al., 2014. O estímulo pelo receptor ainda induz a expressão de quimiocinas, como CCL2, CXCL2, MCP-1, e a produção de mediadores lipídicos como prostaglandinas (Kurashima et al., 2012). O receptor P2X7 é um dos mais potentes ativadores do inflamassoma NLRP3, que resulta na clivagem da caspase-1, e consequentemente, levando a liberação da IL-1ß (Ferrari et al., 2006).

A ativação do receptor P2X7 nas células T decorrente do ATP extracelular leva a uma modificação no volume da célula, resultando primeiramente na exposição da fosdatidilserina na membrana celular, e em seguida na lise celular (Taylor et al., 2008). Apenas um breve estímulo do receptor $P 2 X 7$ já é o suficiente para resultar nesta alteração morfológica, e exposição de fosfatidilserina, entretanto se em até 2030 minutos o estímulo for retirado, o efeito torna-se reversível (Mackenzie et al., 2005). A ativação sustentada do receptor $P 2 X 7$ leva a formação de um poro na membrana celular de até $900 \mathrm{Da}$, o que permite a passagem de solutos pela membrana (Steinberg et al., 1990; Proietti et al., 2014).

O receptor $\mathrm{P} 2 \mathrm{X} 7$ encontra-se distribuído em toda a superfície das células $\mathrm{T}$, o que garante que as células T permaneçam responsivas ao ATP liberado pelos tecidos adjacentes (Figura 3) (Junger et al., 2011). Na sinapse imunológica, as células T expressam também os receptores P2X1 e P2X4 e o P2X7 (Myrtek, Idzko, 2007), que a participação destes receptores amplificam o processo de ativação pelas células T. O ATP é liberado na sinapse imunológica pela célula T através dos canais de Panexina-1, e uma vez no meio extracelular, liga-se aos receptores P2X1, P2X4 e P2X7 e juntamente com a entrada do íon cálcio, amplifica a sinalização 
conduzindo à transcrição da IL-2 (Woehrle et al., 2010), e a diferenciação celular. Ao mesmo tempo, os receptores $\mathrm{P} 2 \mathrm{X} 7$ localizados fora da sinapse imunológica ligandose ao ATP proveniente de outros tecidos que também favorece a ampliação do sinal de ativação das células T (Junger et al., 2011).

Figura 3 Sinalização purinérgica na ativação das célula $T$

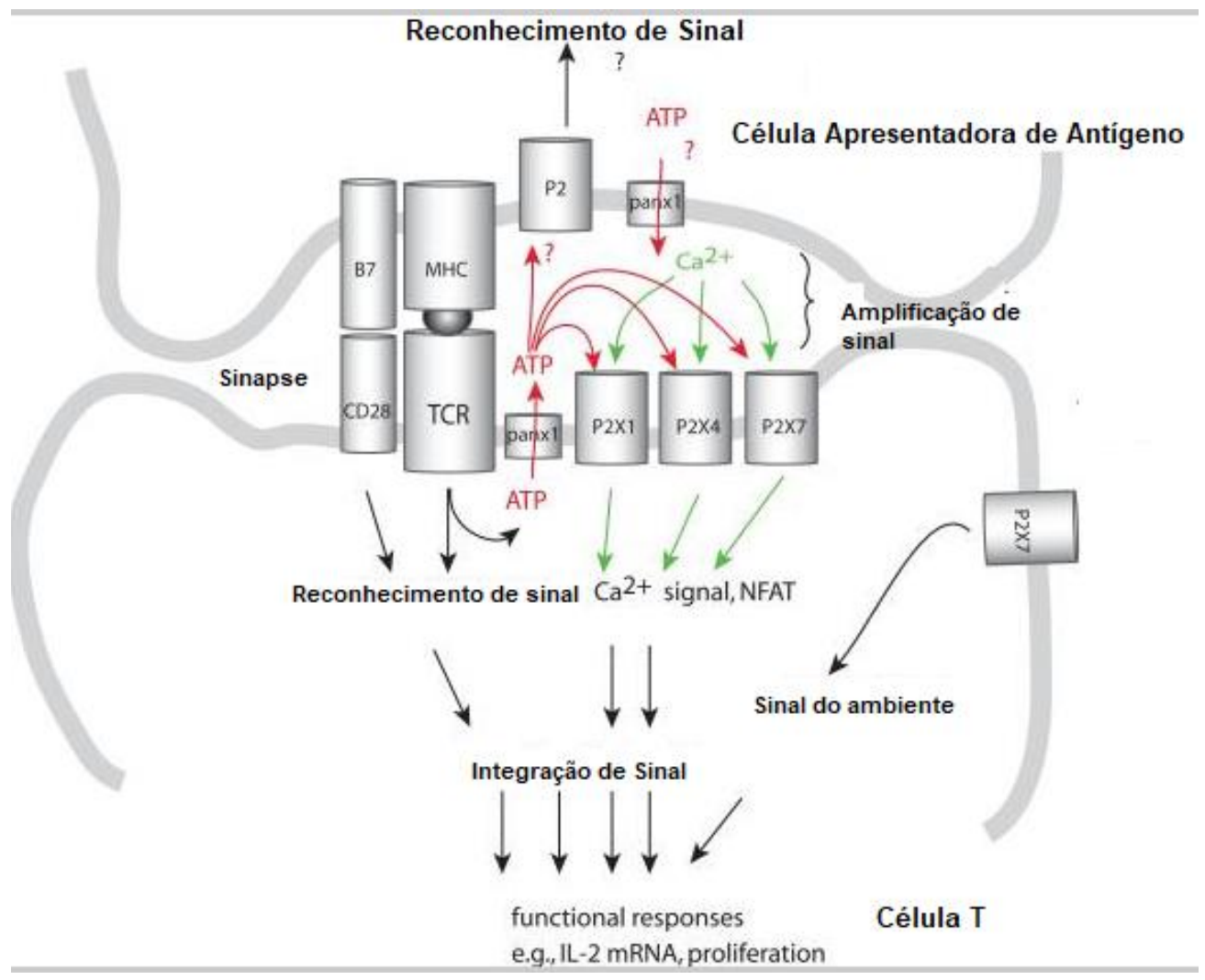

Fonte: Adaptado de Junger et al., 2011

As subpopulações de linfócitos $T$ expressam diferentes quantidades de receptores P2X7 na superfície, e a presença do receptor em altas quantidades na célula resulta na maior sensibilidade desta à morte (Aswad et al., 2006). As células Tfh, expressam exclusivamente o receptor $\mathrm{P} 2 \mathrm{X} 7$, e dentre as células que expressam este receptor em sua superfície, as células Tfh são as que mais expressam. Esta alta expressão do receptor conduz à morte das células Tfh quando expostas ao ATP em altas concentrações (Proietti et al., 2014).

A desenvolvimento de uma vacina eficaz para a malária que envolva a produção de anticorpos de vida longa é fator determinante no controle desta doença. O entendimento dos mecanismos que levam a produção de células Tfh resultante da 
sinalização do P2X7 na malária ainda é pouco conhecido. Esta é uma estratégia que pode ser mais explorada, uma vez que as células Tfh atuam na produção de plasmócitos de vida longa, anticorpos específicos e células $B$ de memória, e a infecção pelo Plasmodium pode estar levando à morte destas células pela alta concentração de ATP no meio extracelular em razão da lise de eritrócitos. 


\section{OBJETIVOS}

\subsection{Objetivo Geral}

- O presente trabalho apresenta como objetivo central avaliar a participação do receptor P2X7 na geração de células Tfh e B do centro germinativo durante a infecção pelo $P$. yoelii 17XNL.

\subsection{Objetivos Específicos}

- Avaliar a participação do receptor P2X7 no controle da infecção pelo $P$. yoelii 17XNL;

- Avaliar a participação do receptor P2X7 na expansão das populações de células T $\mathrm{CD}^{+}$e B durante a infecção pelo $P$. yoelii 17XNL;

- Avaliar a participação do receptor P2X7 na morte das células T CD4+ e B durante a infecção pelo $P$. yoelii 17XNL;

- Avaliar a participação do receptor P2X7 na expressão do fator de transcrição Bcl6 e ICOS em células T CD4+ na infecção pelo $P$. yoelii 17XNL;

- Avaliar a participação do receptor P2X7 na diferenciação das células Tfh nos diferentes dias de infecção pelo $P$. yoelii 17XNL;

- Avaliar a participação do receptor P2X7 no desenvolvimento da população de células $B$ do centro germinativo durante a infecção pelo $P$. yoelii 17XNL;

- Avaliar a participação do receptor P2X7 no desenvolvimento de plasmócitos durante a infecção pelo $P$. yoelii 17XNL;

- Avaliar a participação do receptor P2X7 na produção de anticorpos específicos contra o plasmódio durante a infecção pelo $P$. yoelii 17XNL. 


\section{MATERIAL E MÉTODOS}

\subsection{Comitê de Ética}

Todos os procedimentos experimentais estão de acordo com os regulamentos nacionais de diretrizes éticas para a experimentação e bem estar dos camundongos determinados pelo Conselho Nacional de Controle de Experimentação Animal (CONCEA). Os protocolos foram aprovados pelo Comitê de saúde animal da USP, com o número de licenciamento: 45/2017.

\subsection{Camundongos e infecção}

Para o desenvolvimento desta pesquisa foram utilizados fêmeas de duas linhagens de camundongo C57BL/6 - a linhagem selvagem e linhagem de camundongos deficientes no receptor P2X7 (P2X7-- ) , ambos os camundongos com idades entre 8-10 semanas, fornecidos pelo biotério do Departamento de Imunologia da Universidade de São Paulo (originalmente da The Jackson Laboratory) e mantidos no Biotério de Camundongos Isogênicos Departamento de Imunologia do ICB/USP.

Os camundongos foram infectados pela via intraperitoneal com $1 \times 10^{6}$ reticulócitos infectados pelo $P$. yoelii 17XNL obtidos do sangue de camundongos previamente infectados. O parasito do $P$. yoelii $17 \mathrm{XNL}$ nos foi fornecido pelo $\mathrm{Dr}$. Fábio Trindade Maranhão Costa (UNICAMP). O sangue foi retirado da cauda dos camundongos diluído em Salina tamponada com fosfato (PBS) estéril.

\subsection{Parasitemia e Análise Clínica}

As parasitemias foram monitoradas por meio de exame microscópio de esfregaços sanguíneos corados com Giemsa (Merck, EUA). Uma gota de sangue da cauda do camundongo infectado foi colocada sobre a extremidade inferior de uma lâmina limpa. Utilizando-se uma espátula na angulação de $45^{\circ}$, esta veio ao encontro da borda inferior da lâmina até encostar no sangue, deixando que este conteúdo se difundisse uniformemente por toda a largura da espátula. Em seguida, a espátula, ainda exercendo uma leve pressão sobre a lâmina e mantendo a angulação de $45^{\circ}$, espalhou o conteúdo de sangue até a borda superior. As lâminas contendo o esfregaço do sangue dos camundongos foram feitas diariamente, a partir do 5 dia pós infecção (d.p.i) até a realização do experimento, ou até o dia em que a 
não fosse observado parasito na microscopia. Após a obtenção do esfregaço sanguíneo, as lâminas foram fixadas com metanol e em seguida coradas com Giemsa diluído em água destilada (diluição 1/10). As lâminas foram lidas em microscópio óptico na objetiva 100X utilizando o óleo de imersão (Merck, EUA).

A concentração de hemoglobina foi avaliada com um kit de hemoglobina (Doles Inc., Brasil), sendo determinada a cada dois dias a partir do $3^{\circ}$ dia de infecção.

\subsection{Peso e Suspensão de Células do Baço}

Para obtenção das células do baço, os camundongos foram eutanasiados utilizando halotano (Cristália, Brasil) e o baço foi retirado, sendo então pesado em balança (Denver Instrument, EUA). O baço foi macerado, e as células esplênicas foram lavadas e mantidas em meio RPMI 1640 (Life Technologies, EUA) gelado, suplementado com penicilina/estreptomicina (100 U/ml) (Life Technologies, EUA), Lglutamina (2 mM) (Life Technologies, EUA), piruvato de sódio (1 $\mathrm{mM}$ ) (SigmaAldrich, USA), 3\% de soro bovino fetal (SBF) (Life Technologies, EUA) inativado pelo calor. Para hemólise dos eritrócitos foi utilizado o tampão de lise contendo 1 partes de solução de Tris $(0,5125 \mathrm{~g}$ TRIS Base em $25 \mathrm{ml}$ de água Mili Q) (Sigma-Aldrich) associado a 9 parte de cloreto de amônio $\left(2,14 \mathrm{~g} \mathrm{Nh}{ }_{4} \mathrm{Cl}\right.$ em $25 \mathrm{ml}$ de água Mili Q) (Sigma-Aldrich). Em seguida estas células foram novamente ressuspensas em meio RPMI 1640 para contagem em câmera de Neubauer (HBG, Alemanha)

\subsection{Análise Fenotípica das Células por Citometria de Fluxo}

As células $\left(1 \times 10^{6}\right)$ foram marcadas com uma mistura de anticorpos monoclonais (mAbs) contendo os anticorpos anti-CD4 (RM4-5 ou H129.19, BD Pharmingen, USA) conjugados ao Pacific Blue (PB) e AmCyan, anti-PD-1 (J43, CD279, eBioscience, USA) conjugados à aloficocianina (APC), anti-CXCR5 (CD 185) (SPR CL5 , eBioscience, USA) conjugados ao complexo proteína clorofila peridinina (PerCp) ou à ficoeritrina-Cy7 (PE-Cy-7), anti-ICOS (7E,17G9) conjugados à ficoeritrina (PE-Cy-7), anti-CD95 (JO2; BD Horizon, USA) conjugados ao brilliant violet 510 (BV510), anti-CD19 (ID3, BD Pharmingen, USA) conjugados à ficoeritrinaCy7 (PE-Cy-7), anti-GL-7 (GL7, BD Horizon, USA) conjugados ao brilliant violet 421 (BV421). Para marcação intracelular, mAbs anti-Bcl-6 conjugados à aloficocianinaCy7 (APC-Cy7) (K112-91, BD Pharmingen, USA) foram utilizados de acordo com as 
instruções do fabricante. A viabilidade celular foi determinada com o reagente Live and Dead (LD) (red fluorescence reactive dye ou aqua fluorescence reactive dye) (LifeTechnologies) de acordo com as instruções do fabricante. As amostras foram adquiridas em citômetro de fluxo BD FACS Canto ${ }^{\mathrm{TM}}$ II (Firmware v.1.49) e software BD FACS Diva v.8.0.1. Os dados foram analisados utilizando-se o programa FlowJo v.9.9.8 (Tree Star Inc., USA)

\subsection{Purificação e Sincronização dos Reticulócitos Parasitados}

Esta técnica foi realizada no Laboratório de Imunoparasitologia Experimental do Departamento de Parasitologia do ICB/USP sob a responsabilidade do Dr. Cláudio Romero Faria Marinho. Esta técnica teve como intuito a obtenção de formas maduras do parasita sincronizando os reticulócitos do P. yoelii (Janse et al., 2006). Os reticulócitos de camundongos fêmeas C57BL/6 infectados com o $P$. yoelii foram obtidos do sangue exibindo entre $10-20 \%$ de parasitemia. Os camundongos foram eutanasiados e o sangue foi retirado por punção cardíaca da região atrial, e imediatamente inserido na garrafa para cultura de $75 \mathrm{~cm}$ sem filtro (Corning Inc., USA) já contendo meio de cultura RPMI 1640 (Life Technologies, USA) suplementado com 25\% de SBF (Life Technologies, USA). Em seguida, foi aplicado utilizando uma mangueira acoplada ao fluxo laminar, uma mistura gasosa contendo $5 \%$ de $\mathrm{CO}_{2}, 85 \%$ de $\mathrm{N}_{2}$ e $10 \%$ de $\mathrm{O}_{2}$, durante 30 segundos, cuidando para não romper as células. Em seguida, as garrafas foram armazenadas em estufa a $37^{\circ} \mathrm{C}$ por 14 horas. A seguir, as células foram passadas em uma coluna de separação magnética (Miltenyl Biotec, EUA), que realizou uma seleção positiva, onde teve como intuito a retenção de $10^{7}$ células vermelhas, - uma vez que a coluna apresenta o ferro em sua estrutura, e o ferro facilita a ligação das células vermelhas infectadas pelo parasito, e este produzir hemozoína que tem alta atração pela coluna magnética -. Esta técnica teve como intuito o enriquecimento dos reticulócitos infectados. Em seguida os reticulócitos enriquecidos foram removidos da coluna de magneto. Utilizando-se apenas o êmbolo de yma seringa contendo tampão MACS, aplicou-se este conteúdo sobre a amostra, e retirou-se todo o conteúdo contido na coluna, o qual foi ressuspendidos em tubo falcon. Em seguida o conteúdo foi centrifugado e o sobrenadante descartado. O pellet resultante continha as formas mais maduras do parasito. 


\subsection{Preparação do Extrato do Parasito do $P$. yoelii 17XNL}

Esta etapa teve como referência o protocolo para preparação do extratos de proteína do parasito e análise de western blot (Heiber, Spielmann, 2014). Após a obtenção do pellet contendo as formas maduras do parasito, conforme descrito acima, a primeira etapa para a obtenção do extrato do antígeno foi a retirada da membrana dos reticulócitos parasitados. Adicionou-se ao pellet $1 \mathrm{ml}$ de PBS e a 15 $\mu \mathrm{l}$ de saponina $10 \%$. Lavou-se 5 vezes o conteúdo com $1 \mathrm{ml}$ de PBS, centrifugou-se e descartou-se o sobrenadante. Ao pellet foi adicionado $1 \mathrm{ml}$ de PBS e $5 \mu \mathrm{l}$ do inibidor de protease (Sigma-Aldrich). Por último foi adicionado $135 \mu \mathrm{l}$ de tampão de lise, que continha $4 \mathrm{ml}$ de SDS 10\%, 5ml de Triton X114 10\%, $5 \mathrm{ml}$ de PBS, e 0,5 ml de água destilada em mili Q. Homogeinizou-se o conteúdo que foi sonicado (Sonic Dismembrator - Fischer Scientific, EUA) por 1 minuto. Em seguida dosou-se a concentração da proteína do antígeno. O branco continha 90\% (180 $\mu$ l) de PBS e $10 \%(20 \mu \mathrm{l})$ de tampão de lise do parasito. A placa foi lida no espectrofotômetro (Epoch/Bioteck) utilizando comprimento de onda de 280nm.

\subsection{Titulação do Parasito do $P$. yoelii 17XNL}

Após a obtenção do extrato do parasito, foi realizada a titulação do anticorpo IgM, utilizando a técnica de ELISA descrita abaixo. A partir da dosagem da concentração de proteína do antígeno adquirida na preparação do extrato $(4,5 \mathrm{mg} / \mathrm{l})$ foi realizada uma diluição seriada da concentração deste antígeno tendo como concentração inicial $8 \mu \mathrm{g} / \mathrm{mL}$ com o intuito de identificar uma melhor concentração a ser aplicada que consistiu em $4 \mu \mathrm{g} / \mathrm{mL}$.

\subsection{Detecção por ELISA dos Anticorpos Específicos ao Parasito no Soro}

Anticorpos séricos anti- $P$. yoelii $17 \mathrm{XNL}$ foram detectados por ELISA, a partir do soro obtido dos camundongos controles (dia 0 p.i.) e infectados. O soro foi retirado por coleta do sangue da cauda dos camundongos eutanasiados. $O$ sangue foi armazenado em tubo eppendord de $1,5 \mathrm{~mL}$ contendo $2 \mu \mathrm{L}$ de heparina e centrifugado por 10 minutos em velocidade $2.500 \mathrm{rpm}$. O soro foi então retirado com pipeta e congelado a $-80^{\circ} \mathrm{C}$.

Inicialmente as placas de ELISA (Costar 3590 High Binding - Corning Inc) foram sensibilizadas com $50 \mu \mathrm{L}$ de extrato total de $P$. yoelii diluídos em tampão carbonato/bicarbonato $0,05 \mathrm{M} \mathrm{pH} \mathrm{9,6} \mathrm{e} \mathrm{incubadas} \mathrm{durante} \mathrm{a} \mathrm{noite,} \mathrm{a} 4^{\circ} \mathrm{C}$. Após 
lavagens sucessivas com PBS contendo $0,05 \%$ de tween 20 (Sigma-Aldrich), as placas foram saturadas por 3 horas com $200 \mu \mathrm{l}$ de PBS-tween contendo $1 \%$ de albumina de soro bovino (BSA, Sigma-Aldrich). Após as lavagens, foi adicionado em cada poço, $100 \mu \mathrm{l}$ de diluições decrescentes de cada amostra feitas com PBS-tween contendo $1 \%$ de $\mathrm{BSA}$ e incubados durante a noite a $4^{\circ} \mathrm{C}$. As placas foram lavadas $\mathrm{e}$ a presença de anticorpos específicos contra o parasito, revelada adicionando-se anticorpos de cabra anti-IgM, anti-IgG2c de camundongos conjugados à peroxidase (Southern Biotecnology Associates), diluídos 1:2500 (IgM) e 1:2000 (IgG2C) em PBS-tween com $1 \%$ de BSA. Por fim, as placas foram novamente lavadas e $100 \mu \mathrm{L}$ de Tetrametilbenzidina (TMB) foi adicionado em cada poço. A reação foi bloqueada com $100 \mu$ ácido fosfórico $\left(\mathrm{H}_{3} \mathrm{PO}_{4}\right) 1 \mathrm{M}$ e a leitura, realizada através de um espectofotômetro Spectra Max 190 (Molecular Devices), utilizando o comprimento de onda $450 \mathrm{~nm}$. A concentração do anticorpo é definido a partir da curva do anticorpo que está numa concentração de $1000 \mathrm{ng} / \mathrm{ml}$

\subsection{Análise Estatística}

Todas as análises estatísticas foram realizadas no programa Prisma 6 (GraphPad Prisma 5), com o Teste t de Student, e as diferenças entre os grupos controle e infectado foram consideradas significativas para valores de $p<0,05\left({ }^{*}\right)$, $\left.\left.p<0,01^{(* *}\right), p<0,001^{(* *}\right)$ ou $\left.p<0,0001^{(* * * *}\right)$. 


\section{CONCLUSÃO}

Este estudo mostra que 0 receptor $\mathrm{P} 2 \mathrm{X} 7$ prejudica a expansão das populações de células Tfh e $B$ do centro germinativo do baço, assim como o controle da malária causada pelo $P$. yoelli 17XNL. Os números de células $T C D 4^{+}$, células $B$ e plasmócitos também estão reduzidos quando a infecção ocorre na presença do receptor P2X7. Essa diminuição está associada ao aumento das frequências de células $T \mathrm{CD}^{+}$e $\mathrm{B}$ mortas. Entretanto, a ausência do receptor P2X7 não alterou os níveis séricos de anticorpos $\lg \mathrm{M}$ e $\lg \mathrm{g} 2 \mathrm{c}$ específicos ao parasito. Este estudo contribuiu para a compreensão do papel do receptor P2X7 na geração das células Tfh na malária. 


\section{REFERÊNCIAS}

Adinolfi E, Giuliani AL, De Marchi E, Pegoraro A, Orioli E, Di Virgilio, F. The P2X7 receptor : A main player in inflammation. Biochem Pharmacol. 2018; 151:234-44.

Akkaya C, Shumilina E, Bobballa D, Brand V B, Mahmud H, Lang F, et al.. The Plasmodium falciparum-induced anion channel of human erythrocytes is an ATPrelease pathway. Pflugers Archiv. 2009; 457(5):1035-47.

Allen CD, Okada T, Cyster JG. Germinal-center organization and cellular dynamics. Immunity. 2007; 27(2):190-202.

Aly ASI, Vaughan AM, Kappe SHI. Malaria Parasite Development in the Mosquito and Infection of the Mammalian Host. Annu Rev Microbiol. 2009; 63:195-221.

Amaral EP, Ribeiro SC, Lanes VR, Almeida FM, de Andrade MR, Bomfim CC, et al.. Pulmonary infection with hypervirulent Mycobacteria reveals a crucial role for the P2X7 receptor in aggressive forms of tuberculosis. PLoSPathogens. 2014; 10(7): e1004188.

Amoroso F, Falzoni S, Adinolfi E, Ferrari D, Di Virgilio F. The P2X7 receptor is a key modulator of aerobic glycolysis. Cell Death Dis. 2012; 3:e370.

Aswad F, Dennert G. P2X7 receptor expression levels determine lethal effects of a purine based danger signal in T lymphocytes. Cell Immunol. 2006; 243(1):58-65.

Bagnaresi P, Alves E, Borges da Silva H, Epiphanio S, Mota MM, Garcia CR. Unlike the synchronous Plasmodium falciparum and $P$. chabaudi infection, the $P$. berghei and $P$. yoelii asynchronous infections are not affected by melatonin. Intern J Gen Med. 2009; 2:47-55.

Bartoloni A, Zammarchi L. Clinical aspects of uncomplicated and severe malaria. Mediterr J Hematol Infect Dis. 2012; 4(1):e2012026.

Beeson JG, Chan JA, Fowkes FJI. PfEMP1 as a target of human immunity and a vaccine candidate against malaria. Expert Rev. Vaccines. 2013; 12(2):105-8.

Beeson JG, Mann EJ, Elliott SR, Lema VM, Tadesse E, Molyneux ME, et al. Antibodies to variant surface antigens of Plasmodium falciparum-infected erythrocytes and adhesion inhibitory antibodies are associated with placental malaria and have overlapping and distinct targets. J. Infect. Dis. 2004; 189(3): 540-551.

Bianchi G, Vuerich M, Pellegatti P, Marimpietri D, Emionite L, Marigo I, et al.. ATP/P2X7 axis modulates myeloid-derived suppressor cell functions in neuroblastoma microenvironment. Cell Death Dis. 2014; 5: e1135.

Bouharoun-Tayoun H, Attanath P, Sabchareon A, Chongsuphajaisiddhi T, Druilhe P. Antibodies that protect humans against Plasmodium falciparum blood stages do not on their own inhibit parasite growth and invasion in vitro, but act in cooperation with monocytes. J Exp Med. 1990; 172(6):1633-41.

Bours MJ, Swennen EL, Di Virgilio F, Cronstein BN, Dagnelie PC. Adenosine 5 'triphosphate and adenosine as endogenous signaling molecules in immunity and inflammation. Pharmacol Ther. 2006;112(2):358-404. 
Boyle MJ, Reiling L, Osier FH, Fowkes FJ. Recent insights into humoral immunity targeting Plasmodium falciparum and Plasmodium vivax malaria. Int $\mathrm{J}$ Parasitol. 2017; 47(2-3):99-104.

Braga EM, Barros RM, Reis TA, Fontes CJ, Morais CG, Martins MS, Krettli AU . Association of the IgG response to Plasmodium falciparum merozoite protein (Cterminal $19 \mathrm{kD}$ ) with clinical immunity to malaria in the Brazilian Amazon region. Am. J. Trop. Med Hyg. 2002; 66(5):461-6.

Bredius RG, Fijen CA, De Haas M, Kuijper EJ, Weening RS, Van de Winkel JG, et al. Role of neutrophil Fc gamma RIla (CD32) and Fc gamma RIIlb (CD16) polymorphic forms in phagocytosis of human IgG1- and IgG3-opsonized bacteria and erythrocytes. Immunology. 1994;83(4):624-30.

Breitfeld D, Ohl G, Kremmer E, Ellwart J, Sallusto F, Lipp H, et al . Follicular B Helper T Cells Express Cxc Chemokine Receptor 5, Localize to B Cell Follicles, and Support Immunoglobulin Production. J Exp Med. 2000; 192(11):1545-52.

Burnstock G. Purinergic nerves. Pharmacol Rev. 1972; 24(3):509-81.

Burnstock G. A basis for distinguishing two types of purinergic receptor. In: Cell Membrane Receptors for Drugs and Hormones: A Multidisciplinary Approach, edited by Straub RW and Bolis L.New York: Raven. 1978:107-118.

Burnstock G. Physiology and Pathophysiology of Purinergic Neurotransmission. Physiol Rev. 2007; 87(2):659-797.

Butler NS, Moebius J, Pewe LL, Traore B, Doumbo OK, Tygrett LT, et al.. Therapeutic blockade of PD-L1 and LAG-3 rapidly clears established blood-stage Plasmodium infection. Nat Immunol. 2011; 13(2):188-95.

Carlton JM, Angiuoli SV, Suh BB, Kooij TW, Pertea M, Silva JC et al.. Genome sequence and comparative analysis of the model rodent malaria parasite Plasmodium yoelii yoelii. Nature. 2002; 419:512-19.

Celada A, Cruchaud A, Perrin LH. Opsonic activity of human immune serum on in vitro phagocytosis of Plasmodium falciparum infected red blood cells by monocytes. Clin Exp Immunol. 1982; 47(3):635-44.

Cernetich-Ott A, Daly TM, Vaidya AB, Bergman LW, Burns JM. Remarkable stability in patterns of blood-stage gene expression during episodes of non-lethal Plasmodium yoelii malaria. Malar J. 2012; 11(1):265-81.

Chekeni FB, Elliott MR, Sandilos JK, Walk SF, Kinchen M, Lazarowski ER, et al..Pannexin 1 channel mediate 'find me' signal release and membrane permeability during apoptosis. Nature. 2010; 467(7317):863-7.

Chessell IP, Hatcher JP, Bountra C, Michel AD, Hughes JP, Green P, et al.. Disruption of the P2X7 purinoceptor gene abolishes chronic inflammatory and neuropathic pain. Pain. 2005; 114(3), 386-96.

Chiu CY, Hodder AN, Lin CS, Hill DL, Li Wai Suen CS, Schofield L, et al.. Antibodies to the Plasmodium falciparum proteins MSPDBL1 and MSPDBL2 opsonize 
merozoites, inhibit parasite growth, and predict protection from clinical malaria. J. Infect. Dis. 2015; 212, 406-415.

Choi YS, Eto D, Yang JA, Lao C, Crotty S. Cutting edge: STAT1 is required for IL-6mediated Bcl6 induction for early follicular helper cell differentiation. J Immunol. 2013; 190(7):3049-53.

Choudhury HR, Sheikh NA, Bancroft GJ, Katz DR, de Souza JB. Early nonspecific immune responses and immunity to blood-stage non lethal Plasmodium yoelii malaria. Infect Immun. 2000; 68(11):6127-32.

Coade SB, Pearson JD.. Metabolism of adenine nucleotides in human blood. Circ Res. 1989; 65(3):531-7.

Coban C, Ishii KJ, Kawai T, Hemmi H, Sato S, Uematsu S, et al.. Toll- like receptor 9 mediates innate imune activatioby the malaria pigment hemozoin. J Exp Med. 2005; 201(1):19-25.

Cohen S, McGregor IA, Carrington S. Gamma-globulin and acquired immunity to human malaria. Nature. 1961; 192:733-7.

Couper KN, Blount DG, Wilson MS, Hafalla JC, Belkaid Y, Kamanaka M, et al. IL-10 from CD4CD25Foxp3CD127 adaptive regulatory $T$ cells modulates parasite clearance and pathology during malaria infection. PLoS Pathog. 2008; 4(2): e1000004.

Cowman AF, Crabb BS. Invasion of red blood cells by malaria parasites. Cell. 2006; 124(4): 755-66.

Cowman AF, Healer J, Marapana D, Marsh K. Malaria: Biology and Disease. Cell. 2016; 167(3):610-24.

Cox, FEG. History of the discovery of the malaria parasites and their vectors. Parasites \& Vectors. 2010; 3(1):3-5

Cox-Singh J., Davis TME, Lee KS, Shamsul SS, Matusop A, Ratnam S, Rahman HA, Conway DJ, Singh B. Plasmodium knowlesi malaria in humans is widely distributed and potentially life threatening. Clin Infect Dis. 2008; 46(2):165-71.

Crotty S. Follicular helper CD4 T cells (TFH). Annu Rev Immunol. 2011; 29:621-63.

Crutcher JM, Hoffman SL. Malaria. In: Baron S, editor. Medical Microbiology. 4th ed. Galveston (TX): University of Texas Medical Branch at Galveston; 1996.

Daneshvar C, Davis TM, Cox-Singh J, Rafa'ee MZ, Zakaria SK, Divis PC, et al. Clinical and laboratory features of human Plasmodium knowlesi infection. Clin Infect Dis. 2009; 49(6):852-60.

Dankwa DA, Davis MJ, Kappe SHI, Vaughan M. A Plasmodium yoelii Mei2-Like RNA Binding Protein Is Essential for Completion of Liver Stage Schizogony. Infect Immun. 2016; 84(5):1336-45. 
Di Virgilio F, Bronte V, Collavo D, Zanovello P. Responses of mouse lymphocytes to extracellular adenosine 5 -triphosphate (ATP). Lymphocytes with cytotoxic activity are resistant to the permeabilizing effects of ATP. J. Immunol. 1989; 143(6),1955-60.

Di Virgilio F, Borea PA, Illes P. P2 receptors meet the imune system. Trends Pharmacol. 2001; 22(1): 5-7.

Di Virgilio F. Novel data point to a broader mechanism of action of oxidized ATP: the P2X7 receptor is not the only target. Br J Pharmacol. 2003; 140(3):441-3.

Di Virgilio F, Boeynaems JM, Robson SC. Extracellular nucleotides as negative modulators of immunity. Curr Opin Pharmacol. 2009; 9(4):507-13.

Di Virgilio F, Dal Ben D, Sarti AC, Giuliani AL, Falzoni S. The P2X7 Receptor in Infection and Inflammatio. Immunity. 2017; 47(1): 15-31

Doolan DL, Dobaño C, Baird JK. Acquired immunity to malaria. Clin Microbiol Rev. 2009; 22(1):13-36

Dostert C, Guarda G, Romero JF, Menu P, Gross O, Tardivel A et al. Malarial Hemozoin Is a Nalp3 Inflammasome Activating Danger Signal. Plos One. 2009; 4(8):e6510.

Egan AF, Morris J, Barnish G, Allen S, Greenwood BM, Kaslow DC, Holder AA, Riley EM. Clinical immunity to Plasmodium falciparum malaria is associated with serum antibodies to the $19-\mathrm{kDa}$ C-terminal fragment of the merozoite surface antigen, PfMSP-1.J. Infect Dis. 1996; 173(3):765-9.

Ettinger R, Sims GP, Fairhurst AM, Robbins R, da Silva YS, Spolski R, Leonard WJ, et al.. IL-21 Induces Differentiation of Human Naive and Memory B Cells into Antibody-Secreting Plasma Cells. J Immunol. 2005; 175(12):7867-79.

Ferrari D, La Sala A, Chiozzi P, Morelli A, Falzoni S, Girolomoni G, et al.. The P2 purinergic receptors of human dendritic cells: identification and coupling to cytokine release. FASEB J. 2000; 14(15):2466-76.

Ferrari D, Pizzirani C, Adinolfi E, Lemoli RM, Curti A, Idzko M, et al.. The P2X7 receptor: a key player in IL-1 processing and release. J. Immunol. 2006; 176(7): 3877-83.

Figueiredo MM, Costa PAC, Diniz SQ, Henriques PM, Kano FS, Tada MS,et al.. T follicular helper cells regulate the activation of $B$ lymphocytes and antibody production during Plasmodium vivax infection. PLoS Pathog. 2017; 13(7):e1006484.

Francis S E, Sullivan DJ,Goldberg D E. Hemoglobin metabolism in the malaria parasite Plasmodium falciparum. Annu Rev. Microbiol. 1997; 51:97-123.

Good-Jacobson KL, Shlomchik MJ.. Plasticity and heterogeneity in the generation of memory B cells and long-lived plasma cells: the influence of germinal center interactions and dynamics. J Immunol. 2010; 185(6):3117-25.

Good MF, Doolan DL. Malaria vaccine design: immunological considerations. Immunity. 2010; 33(4):555-66. 
Guthmiller JJ, Graham AC, Zander RA, Pope RL, Butler NS. Cutting Edge: IL-10 Is Essential for the Generation of Germinal Center B Cell Responses and AntiPlasmodium Humoral Immunity. J Immunol. 2017; 198(2):617-622.

Hahn WO, Butler NS, Lindner SE, Akilesh HM, Sather DN, Kappe SH, Hamerman $\mathrm{JA}$, et al.. cGAS-mediated control of blood-stage malaria promotes Plasmodiumspecific germinal center responses. JCI Insight. 2018; 3(2): 94142.

Hansen DS, Obeng-Adjei N, Ly A, loannidis LJ, Crompton PD. Emerging concepts in T follicular helper cell responses to malaria. Int J Parasitol. 2017; 47(2-3):105-110.

Haynes NM, Allen CDC, Lesley R, Ansel KM, Killeen N, Cyster JG. Role of CXCR5 and CCR7 in follicular Th cell positioning and appearance of a programmed cell death gene-1 high germinal center-associated subpopulation. J Immunol. 2007; 179(8): 5099-108.

Heiber, A., Spielmann T.. (2014) Preparation of parasite extracts and westerm blot Analysis. Bio-protocol. 4: 1-10. [acesso em abr 2017]. Disponível em: https://bioprotocol.org/pdf/bio-protocol1136.pdf.

Hill DL, Eriksson EM, Li Wai Suen CS, Chiu CY, Ryg-Cornejo V, Robinson LJ, et al. Opsonising antibodies to $P$. falciparum merozoites associated with immunity to clinical malaria. PLoS One, 2013; 8(9):e74627.

James KR, Soon MSF, Sebina I, Fernandez-Ruiz D, Davey G, Liligeto UN, et al.. IFN regulatory fator 3 balances Th1 ant $T$ follicular helper immunity during nonlethal blood-stage Plasmodium infection. J Immunol. 2018; 200(4):1443-56.

Janse, C. J., Ramesar, J., Waters, A. P.. High-efficiency transfection and drug selection of genetically transformed blood stages of the rodent malaria parasite Plasmodium berghei. Nat Protoc. 2006; 1(1):346-345.

Junger WG. Immune cell regulation by autocrine purinergic signalling. Nat Rev Immunol. 2011; 11(3):201-12.

Kerfoot SM, Yaari G, Patel FR, Johnson KL, Gonzalez DG, Kleinstein SH, et al.. Germinal center B cell and $\mathrm{T}$ follicular helper cell development initiates in the interfollicular zone. Immunity. 2011; 34(6):947-60.

Khusmith S, Druilhe P, Gentilini M. Enhanced Plasmodium falciparum merozoite phagocytosis by monocytes from immune individuals. Infect Immun. 1982; 35(3):8749.

Khusmith $\mathrm{S}$, Druilhe $\mathrm{P}$. Antibody-dependent ingestion of $P$. falciparum merozoites by human blood monocytes. Parasite Immunol. 1983; 5(4):357-68.

Krishnegowda G, Hajjar AM,Shu J, Douglass EJ, Uematsu S, Akira S, Woods AS, Gowda DC. Induction of proinlammatory responses in macrophages by the glycosylphosphatidylinositols of Plasmodium falciparum: cell signaling receptors, glycosylphosphatidylinositol (GPI) structural requirement, and regulation of GPI activity. J Biol Chem. 2005; 280(9):8606-16. 
Kurashima Y, Amiya T, Nochi T, Fujisawa K, Haraguchi T, Iba H, et al.. Extracellular ATP mediates mast cell-dependent intestinal inflammation through P2X7 purinoceptors. Nat. Commun. 2012; 3:1034.

Li J, Pattaradilokrat S, Zhu F, Jiang H, Liu S, Hong L, et al.. Linkage maps from multiple genetic crosses and loci linked to growth - related virulent phenotype in Plasmodium yoelii. Proc Natl Acad Sci USA. 2011;108(31):374-82.

Liu X, Yan X, Zhong B, Nurieva RI, Wang A, Wang X, et al.. Bcl6 expression specifies the $T$ follicular helper cell program in vivo. J Exp Med. 2012; 209(10):184152.

Locovei S, Bao L, Dahi G. Pannexin 1 in erythrocytes: function without a gap. Proc Natl Acad Sci USA. 2006; 103(20):7655-9

Long CA, Daly TM, Kima P, Srivastava,I. Immunity to erythrocytic stages of malarial parasites. Am J Trop Med Hyg. 1994; 50(4suppl):27-32.

Mackenzie AB, Young MT, Adinolfi E, Surprenant A. Pseudoapoptosis induced by brief activation of ATP-gated P2X7 receptors. J Biol Chem. 2005; 280(40):33968-76.

Marsh K, Kinyanjui S. Immune effector mechanisms in malaria. Parasite Immunol. 2006; 28(1-2):51-60.

Meding SJ, Cheng SC, Simon-Haarhaus B, Langhorne J. Role of gamma interferon during infection with Plasmodium chabaudi chabaudi. Infection and immunity. 1990; 58(11):3671-8.

Ménard R. The journey of the malaria sporozoite through its hosts: two parasite proteins lead the way. Microbes Infect. 2000; 2(6):633-42.

Metzger WG, Okenu DM, Cavanagh DR, Robinson JV, Bojang KA, Weiss HA, McBride JS, Greenwood BM, Conway DJ. Serum IgG3 to the Plasmodium falciparum merozoite surface protein 2 is strongly associated with a reduced prospective risk of malaria. Parasite Immunol. 2003; 25(6):307-12.

Ministério da Saúde (BR), Secretaria de Vigilância em Saúde. Boletim Epidemiológico Malária: Monitoramento dos casos no Brasil em 2014. Brasília (DF); 2015.

Ministério da Saúde (BR). Malária [acesso em jul 2017]. Disponível em: <http:// portalms.saude.gov.br/saude-de-a-z/malária>.

Monção-Ribeiro LC, Faffe DS, Santana PT, Vieira FS, da Graça CL, Marques-daSilva $\mathrm{C}$, et al.. P2X7 receptor modulates inflammatory and functional pulmonary changes induced by silica. PLoS ONE. 2014; 9(10):e110185.

Morita R, Schmitt N, Bentebibel SE, Ranganathan R, Bourdery G, Zurawski L, et al.. Human Blood CXCR5 ${ }^{+} \mathrm{CD} 4{ }^{+} \mathrm{T}$ Cells Are Counterparts of $\mathrm{T}$ Follicular Cells and Contain Specific Subsets that Differentially Support Antibody Secretion. Immunity. 2011; 34(1):108-21.

Myrtek D, Idzko M. Chemotactic activity of extracelular nucleotides on human imune cells. Purinergic Signal. 2007;3(1-2): 5-11. 
Moormann AM, Sumba PO, Chelimo K, Fang H, Tisch DJ, Dent AE, John CC, Long CA, Vulule J, Kazura JW. Humoral and cellular immunity to Plasmodium falciparum merozoite surface protein 1 and protection from infection with blood-stage parasites. J. infection Dis. 2013; 208(1):149-58

Mueller I, Galinski MR, Tsuboi T, Arevalo-Herrera M, Collins WE, King CL. Natural acquisition of immunity to Plasmodium vivax: epidemiological observations and potential target. Adv Parasitol. 2013; 81:77-131.

North, R. A. Molecular Physiology of P2X Receptors. Physiol Rev. 2002; 82(4), 1013-1067.

Nurieva RI, Chung Y, Hwang D, Yang XO, Kang HS, Ma L, et al.. Generation of T follicular helper cells is mediated by interleukin-21 but independent of $\mathrm{T}$ helper 1, 2, or 17 cell lineages. Immunity. 2008; 29(1):138-49.

Nurieva RI, Podd A, Chen Y, Alekseev AM, Yu M, Qi X,et al.. STAT5 protein negatively regulates $T$ follicular helper (Tfh) cell generation and function. $J$ Biol Chem. 2012; 287(14):11234-9.

Obeng-Adjei N, Traore B, Crompton PD, Tran TM, Yazew TB, Skinner J, et al. Circulating Th1-Cell-type Th Cells that Exhibit Impaired B Cell Help Are Preferentially Activated during Acute Malaria in Children Article Circulating Th1-Celltype Tfh Cells that Exhibit Impaired B Cell Help Are Preferentially Activated during Acute Malaria. Cell Rep. 2015; 13(2):425-39.

Omer FM, de Souza JB, Riley EM. Differential induction of TGF-beta regulates proinflammatory cytokine production and determines the outcome of lethal and nonlethal Plasmodium yoelii infections. J Immunol. 2003; 171(10):5430-6.

Organização Pan-Americana de Saúde [internet]. Brasília: Casos de malária aumentam na região das Américas; 2018 [acesso em mai 2018]. Disponível em:<https://www.paho.org/bra/index.php?option=com_content\&view=article\&id=5591 :casos-de-malaria-aumentam-na-regiao-das-americas\&ltemid=812>.

Pérez-Mazliah D, Ng DH, Freitas do Rosário AP, McLaughlin S, Mastelic Gavillet B, Sodenkamp J, et al.. Disruption of IL-21 signaling affects T cell-B cell interactions and abrogates protective humoral immunity to malaria. PLoS Pathogens. 2015; 11(3): e1004715.

Pérez-Mazliah D, Nguyen MP, Hosking C, McLaughlin S, Lewis MD, Tumwine I, et al.. Follicular helper T cells are essential for elimination of Plasmodium infection. EBioMedicine. 2017; 24:216-230.

Perry JA, Olver CS, Burnett RC, Avery AC. Cutting edge: the acquisition of TLR tolerance during malaria infection impacts T cell activation. J Immunol. 2005; 174 (10):5921-5.

Polley SD, Conway DJ, Cavanagh DR, McBride JS, Lowe BS, Williams TN , Mwangi TW , Marsh K. High levels of serum antibodies to merozoite surface protein 2 of Plasmodium falciparum are associated with reduced risk of clinical malaria in coastal Kenya. Vaccine. 2006; 24(19):4233-46. 
Pombo DJ. Lawrance G, Hirunpetcharat C, Rzepczyk C, Bryden M, Cloonan N, AndersonK, Mahakunkijcharoen Y, Martin LB, Wilson D, Elliott S, Elliott S, Eisen DP, Weinberg JB, Saul A, GoodMF. Immunity to malaria after administrationof ultra-low doses of red cells infected with Plasmodium falciparum. Lancet. 2002; 360(9333):610-7.

Proietti M, Cornacchione V, Rezzonico Jost T, Romagnani A, Faliti C E, Perruzza L, et al.. ATP-gated ionotropic P2X7 receptor controls follicular $\mathrm{T}$ helper number in Peyer's patches to promote host-microbiota mutualism. Immunity. 2014; 41(5):789801.

Raja AI, Cai Y, Reiman JM, Groves P, Chakravarty S, Mcphun V, et al. Chemically attenuated blood-stage Plasmodium yoelii parasites induce long-lived and straintranscending protection. Infect Immun. 2016; 84(8):2274-88.

Robson SC, Sévigny J, Zimmermann H.The E-NTPDase family of ectonucleotidases: Structure function relationships and pathophysiological significance. Purinergic Signal. 2006; 2(2):409-30.

Rousset F, Garcia E, Defrance T, Péronne C, Vezzio N, Hsu DH, et al.. Interleukin 10 is a potent growth and differentiation factor for activated human B lymphocytes. Proc Natl Acad Sci USA. 1992; 89(5):1890-3.

Salles ÉM, Menezes MN, Siqueira R, Borges da Silva H, Amaral EP, CastilloMéndez SI, et al.. P2X7 receptor drives Th1 cell differentiation and controls the follicular helper $\mathrm{T}$ cell population to protect against Plasmodium chabaudi malaria. PLoS Pathogens. 2017; 13(8): e1006595.

Sayles PC, Wassom DL. Plasmodium yoelii : Antibody Response in Resistant Mouse Strains and Susceptible. Experimental Parasitology. 1991; 73, 241-248.

Sebina I, Fogg LG, James KR, Soon MSF, Akter J, Bryce S, et al.. IL-6 promotes $\mathrm{CD}^{+} \mathrm{T}$-cell and B-cell activation during Plasmodium infection. Parasite Immunol. 2017; 39(10).

Sebina I, James KR, Soon MSF, Fogg LG, Best SE, Labastida Rivera F. et al.. IFNAR1-signalling obstructs ICOS-mediated humoral immunity during non-lethal blood-stage Plasmodium infection. PLoS Pathogens. 2016; 12(11): e1005999.

Seong SY, Matzinger P. Hydrophobicity: an ancient damage-associated molecular pattern that initiates innate immune responses. Nat Rev Immunol. 2004; 4(6):469-78.

Schofield L, Hackett F. Signal transduction in host cells by a glycosylphosphatidylinositol toxin of malaria parasites. J. Exp Med. 1993; 177(1):14553

Silvie O, Mota MM, Matuschewski K, Prude M. Interactions of the malaria parasite and its mammalian host. Curr Opin Microbiol. 2008; 11(4):352-9.

Stanisic DI, Richards JS, McCallum FJ, Michon P, King CL, Schoepflin S, et al.. Immunoglobulin $G$ subclass-specific responses against Plasmodium falciparum merozoite antigens are associated with control of parasitemia and protection from symptomatic illness. Infect Immun. 2009; 77(3):1165-74. 
Steinberg TH, Buisman HP, Greenberg S, Di Virgillio F, Silverstein SC. Effects of extracellular ATP on mononuclear phagocytes. Ann N Y Acad Sci. 1990; 603:120-9.

Stephens R, Culleton RL, Lamb TJ. The contribution of Plasmodium chabaudi to our understanding of malaria. Trends Parasitol. 2012; 28(2):73-82.

Stubbs J, Olugbile S, Saidou B, Simpore J, Corradin G, Lanzavecchia A. Straintranscending Fc-dependent killing of Plasmodium falciparum by merozoite surface protein 2 allele-specific human antibodies. Infect Immun. 2011; 79(3):1143-52.

Sturm A, Amino R, van de Sand C, Regen T, Retzlaff S, Rennenberg A, Krueger A, Pollok JM, Menard R, Heussler VT. Manipulation of host hepatocytes by the malaria parasite for delivery into liver sinusoids. Science. 2006; 313:1287-90.

Tan SY, Ahana A. Charles Laveran (1845-1922): Nobel laureate pioneer of malaria. Singapore Med J. 2009; 50(7):657-8.

Tangye SG, Ma CS, Brink R, Deenick EK. The good, the bad and the ugly - TFH cells in human health and disease. Nat Rev Immunol. 2013; 13(6):412-26.

Taylor SR, Gonzalez-Begne M, Dewhurst S, Chimini G, Higgins CF, Melvin JE, Elliott Jl. Sequencial shrinkage and swelling underlie P2X7-stimulated lymphocyte phosphatidylserine exposure and death. J Immunol. 2008; 180(1):300-8.

Taylor RR, Allen SJ , Greenwood BM , Riley EM . IgG3 antibodies to Plasmodium falciparum merozoite surface protein 2 (MSP2): increasing prevalence with age and association with clinical immunity to malaria. Am. J. Tro. Med. Hyg. 1998; 58(4):40613.

Taylor RR, Smith DB, Robinson VJ, McBride JS, Riley EM. Human antibody response to Plasmodium falciparum merozoite surface protein 2 is serogroup specific and predominantly of the immunoglobulin G3 subclass. Infect Immun. 1995; 63(11): 4382-8.

Teo A, Feng G, Brown GV, Beeson JG, Rogerson SJ. Functional antibodies and protection against blood-stage Malaria. Trends Parasitol. 2016; 32(11):887-98.

Tran TM, Li S, Doumbo S, Doumtabe D, Huang CY, Dia S, Bathily A, Sangala J, Kone Y, Traore A, Niangaly M, Dara C, Kayentao K, Ongoiba A, Doumbo OK, Traore $\mathrm{B}$, Crompton PD. An intensive longitudinal cohort study of Malian children and adults reveals no evidence of acquired immunity to Plasmodium falciparum infection. Clin Infect Dis. 2013; 57(1):40-47.

Tran TM, Samal B, Kirkness E, Crompton PD. Systems immunology of human malaria. Trends Parasitol. 2012; 28(6):248-57.

Ueffing $\mathrm{K}$, Abberger $\mathrm{H}$, Westendorf AM, Matuschewski K, Buer J, Hansen W. Conventional CD11c high dendritic cells are important for $\mathrm{T}$ cell priming during the initial phase of Plasmodium yoelii infection, but are dispensable at later time points. Front Immunol. 2017;8:1333

World Health Organization [internet]. Genebra: World Malaria Report 2017; 2017 [acesso em: jan. 2018]. Disponível em: <http://apps.who.int/iris/bitstream/handle/ 10665/259492/9789241565523-eng.pdf>. 
Woehrle T, Yip L, Elkhal A, Y Sumi, Chen Y, Yao Y et al. . Pannexin-1 hemichannelmediated ATP release together with P2X1 and P2X4 receptors regulate T-cell activation at the immune synapse. Blood. 2010; 116(18):3475-84.

Xu H, Liu J, Cui X, Zuo Y, Zhang Z, Li Y,et al.. Increased frequency of circulating follicular helper $T$ cells in lupus patients is associated with autoantibody production in a CD40L-dependent manner. Cell Immunol. 2015; 295(1):46-51.

Zander RA, Guthmiller JJ, Graham AC, Pope RL, Burke BE, Carr DJ, et al.. Type I Interferons Induce $T$ Regulatory 1 Responses and Restrict Humoral Immunity during Experimental Malaria.PLoS Pathog. 2016; 12(10):e1005945.

Zander RA, Obeng-Adjei N, Guthmiller JJ, Kulu DI, Li J, Ongoiba A, et al.. PD-1 coinhibitory and OX40 co-stimulatory crosstalk regulates helper $T$ cell differentiation and anti-Plasmodium humoral immunity. Cell Host Microbe. 2015; 17(5):628-641. 
APÊNDICE A - P2X7 receptor drives Th1 cell differentiation and controls the follicular helper $T$ cell population to protect agains Plasmodium chabaudi malaria

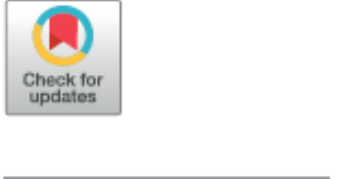

Gopenaccess

Catcon:Sale Éne, Marezs Mud, Siquảa R,

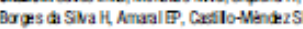
efi. (2017) P2X7 roophor a ive Th1 as

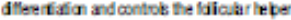

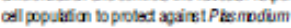

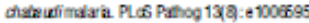

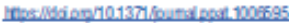

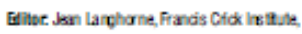
UNITE KINGDOM

Receinet Mrdi22, 2017

hosepta: / host 21,2017

Pallistet hogas 31, 2017

Caprift: exp17 Sales a d Tis is a ope acoss arive dist b ted under the lerms d the

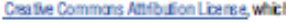
pemts unseticiad ux, gatibifon and

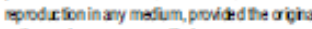
affor and save at cestest

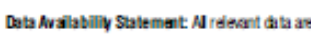
wein te paper andits Suposing ifomition fies.

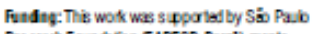
Fesardif Fondison (FNPESP, Brai) gants, $201051150-4,20130 \pi 40-2$ and 2015/20132-8 MFOL) and Narond Courcilibr Sadific and



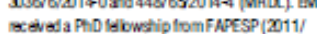

RESEARCHARTCLE

P2X7 receptor drives Th1 cell differentiation and controls the follicular helper $\mathrm{T}$ cell population to protect against Plasmodium chabaudi malaria

Érika Machsdo de Salles' $*$, Maria Nogueira de Menezes', Renan Siqueira', lsabela Cunha', Alexandra dos Anjos Cassado ', Flávia Sarmentb Veira', David Nicholas Olivieri', Carlos Eduardo Tadokoro
Silva , José Maria Alvarez', Robson Coutinho-

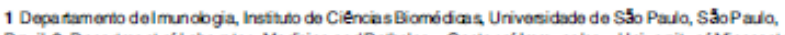

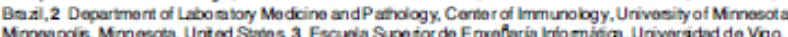

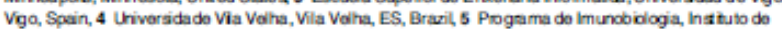

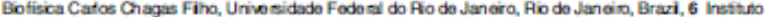

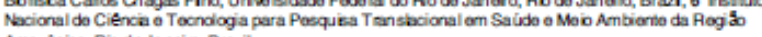
Arrazónca, Rio do Janain, Bravil

- atkasallos Qqumai.omm (EMS); rolima Quso.br MPOL)

\section{Abstract}

A complete understanding of the mechanisms underlying the acquisition of protective immunity is crucial to improve vaccine strategies to eradica te malaria. However, it is still unclear Whether recognifion of damage signals influences the immune response to Plasmodium infection. Adenosine triphosphate (ATP) accumulates in infected erythrocyles and is released $\mathbf{n}$ to the extracellular milieu through bn channels in the erythrocyte membrane or upon erythrocyte rupture. The P2X7 receptor senses extracellular ATP and induces CD4 T cell activation and death. Here we show that P2X7 receptor promotes T helper 1 (Th1) cell differentiation to the detriment of follicular $\mathrm{T}$ helper (Tfh) cells during blood-stage Plasmodium chabaudi malaria. The $\mathrm{P} 2 X 7$ recep tor was a ctivated in CD4 T cells following the rupture of infected erythrocytes and these cells became highly responsive to ATP during acute infection. Moreover, mice lacking the P2X7 recep tor had increased susceptbility to infecfion, which correlated with impaired Th1 cell differentiation. Accordingly, IL-2 and IFNY secretion, as well as T-bet expres sion, critcally depended on P2X7 signaling in CD4 T cells. Additionally, P2X7 receptor controlled the splenic Tth cell population in infected mice by promoting apoptotic-like cell death. Finally, the P2X7 receptor was required to generate a balanced Th1/Tth cell population with an improved ability to transfer parasite protection to

CD4-deficient mice. This study provides a new insight into malaria immunology by showing the importance of P2X7 receptor in $\infty$ ntrolling the fine-tuning be tween Th1 and Th cell differentiation during $P$. chabaudi infection and thus in dise ase outcome. 


\section{APÊNDICE B - The Brazilian Zika virus strain causes birth defects in experimental models}

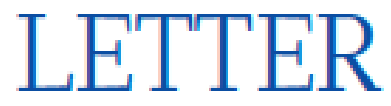

\section{The Brazilian Zika virus strain causes birth defects in experimental models}

Fernanda R. Cugola ${ }^{1}$, Isabella R. Fernandes 1,24 , Fabiele B. Russo 1,34 , Bearriz C. Freitas ${ }^{2}$, Joăo L. M. Dias ${ }^{1}$, Karia P. Guimaraes ${ }^{1}$,

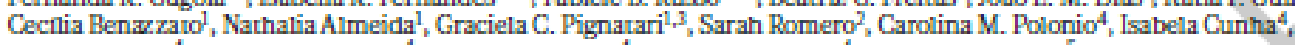
Carla L. Freiras ${ }^{4}$, Wesley N. Brandao ${ }^{4}$, Cristiano Rossato 4 , David G. Andrade 4 , Daniele de P. Paria ${ }^{5}$, Alexandre I Garcer 5 Carlos A. Buchpigel 5 , Carla T. Braconir, Erica Mendes ${ }^{6}$, Amadou A. Sall 7 , Paolo M. de A. Zanouo ${ }^{6}$, Jean Pierre S. Peron ${ }^{4}$, Alysson R. Muotri ${ }^{2}$ \& Patricia C. B. Belurao-Braga ${ }^{1,8}$

Zika virus (ZIKV) is an arbovirus belonging to the genus Flavivirus (family Flaviviridae) and was first described in 1947 in Uganda following blood analyses of sentinel Rhesus monkeys'. Until the twentieth century, the African and A sian lineages of the virus did not cause meaningful infections in humans. However, in 2007 , vectored by Aedes aegypti mosquitoes, ZIKV caused the first noteworthy epidemic on the Yap Island in Micronesia ${ }^{2}$. Patients experienced fever, skin rash, arthralgia and conjunctivitis ${ }^{2}$. From 2013 to 2015 , the Asian lineage of the virus caused further massive outbreaks in New Caledonia and French Polynesia. In 2013, ZIKV reached Brazil, later spreading to other countries in South and Central America ${ }^{3}$. In Brazil, the virus has been linked to congenital malformations, including microcephaly and other severe neurological diseases, such as Guillain-Barré syndrome ${ }^{4,5}$. Despite dinical evidence, direct experimental proof showing that the Brazilian ZIKV (ZIKV ${ }^{32}$ ) strain causes birth defects remains absent $t^{6}$. Here we demonstrate that $Z I K V^{32}$ infects fetuses, causing intrauterine growth restriction. including signs of microcephaly, in mice. Moreower, the virus infects human cortical progenitor cells, leading to an increase in cell death. We also report that the infection of human brain organoids results in a reduction of proliferative zones and disrupted cortical layers. These results indicate that $\mathrm{ZIKV}^{\mathrm{BR}}$ crosses the placenta and causes microcephaly by targeting cortical progenitor cells, inducing cell death by apoptosis and autophagy, and impairing neurodevelopment. Our data reinforce the growing body of evidence linking the ZIKV ${ }^{\mathrm{Z} Z}$ outbreak to the alarming number of cases of congenital brain malformations. Our model can be used to determine the efficiency of therapeutic approaches to counteracting the harmful impact of $\mathrm{ZIKV}^{\mathrm{Bn}}$ in human neurodevelopment.

The recent increase in microcephaly cases in Brazill has been assoclated with the outbreak of Zika virus (ZIKV) ${ }^{7}$, orlginating from an Astan-lineage strain that can be spread by Aedes aegyptl mosquitoes". The Brazillan ZIKV (ZIKV ${ }^{\mathrm{II}}$ ) has been detected in the placenta and amnlotic flutd of two women with microcephalic fetuses ${ }^{2-11}$ and in the blood of microcephalic newborns ${ }^{1012}$, suggesting that the virus can cross the placental membrane. The virus has also been identifled in the brains and retinas of microcephalic fetuses ${ }^{11-13}$. However, there is no direct eridence of the mechanlism by which ZIKV ${ }^{\mathrm{BR}}$ causes brain malformations. A previous study revealed that the African ZIKV $\left(\mathrm{ZIKV} \mathrm{K}^{\mathrm{N}}\right.$, strain MR-766) has the ablity to infect human skin cells ${ }^{14}$ Neurons and astrocytes in the mouse brain could also be infected. inducing hippocampal degeneration and necrosts of pyriform cells
7 days post-infection ${ }^{15}$. More recently, ZIKV ${ }^{0 / 7}$ was also shown to infect human pluripotent stem cell (hPSC)-derived neural progenttor cells (NPCs) in vitro, which induced apoptotic cell death ${ }^{16}$. These studies were performed usting the MR-766 ZKKV strain isolated in Uganda in 1947, which shares $87-90 \%$ sequence simllartiy with the Polynestan and Brazilian isolates ${ }^{2}, 17$. Nevertheless, because severe congenttal malformathons were not reported for African isolates, there is a need to study the association of ZIKV with microcephaly and birth defects with isolates from affected localntles, such as the ZIKV ${ }^{\mathrm{BR}}$ strain. Therefore, there is an urgent need to develop model systems to determine the relationship between infection with the ZIKV ${ }^{i n h}$ strain and birth defects.

We used ZIKV ${ }^{\mathrm{RR}}$ isolated from a febrlle case in the state of Paraiba, in the northeast of Brazil in 2015 (see Methods). To evaluate the causal relationship between ZIKV ${ }^{\mathrm{zII}}$ and birth defects, including brain malformation during development, we flrst used a murine expertmental model in which SIL and C57BL/6 pregnant mice were infected with ZIKV ${ }^{\mathrm{II}}$, evaluating newborns immediately after birth (Extended Data Fig. 1a). Notably, stmilar to ZIKV ${ }^{\text {BR }}$-Infected human newborns ${ }^{15,19}$. pups born from the SIL. ZIKV ${ }^{\mathrm{ER}}$-infected pregnant females displayed clear evidence of whole-body growth delay or intra-uterine growth restriction (IUGR) ${ }^{20}$ compared to pups born from the mock-infected controls (Fig. 1a, b). Using a qPCR assay, we confirmed the presence of

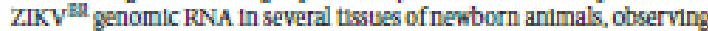
significantly more viral RNA in the brain, conflirming the neurotropic nature of the virus (Fig. IC).

Microcephaly is perhaps the most dramatic of the birth defects reported in ZIKV ${ }^{\text {Eir }}$-infected newborns ${ }^{4,18,19}$. Mouse models often fal to reproduce the severely reduced brain stze and pathological alterattons found in human pattents ${ }^{21,22}$, probably owing to slgnificant differences in gestation time and brain development between the two specles. Nevertheless, upon close inspectlon of the ZIKV ${ }^{\text {III }}$-infected mice brains, we noticed cortical malformations in the surviving animals, with reduced cell number and cortical layer thickness, signs assoctated with microcephaly in humans (Fig. 1d-f). At a cellular level the neurons in the cortex, thalamus and hypothalamus displayed a 'vacuolar nuclel' appearance. 'This morphology was charactertzed by central emptiness and marginalized chromatin pattern with nuclear debris, suggesting ongolng cellular death (Fig. 1 d and Extended Data Flg. 2). In addition, we also noticed apparent ocular abnormalittes, reminiscent of that observed in human patients ${ }^{23}$ (Pig. 1g). Thus, SJL. infected pups presented congenital malformations compatible with $\mathrm{ZIKV}^{\mathrm{Bn}}$-infected human newborns. While the impact of ZIKV ${ }^{\mathrm{BI}}$

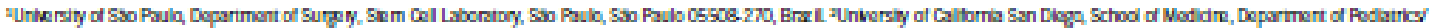

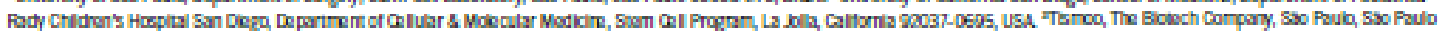

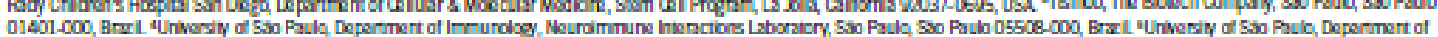

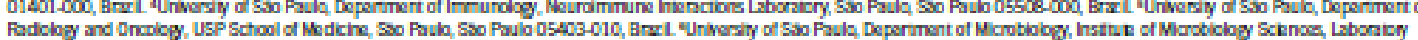

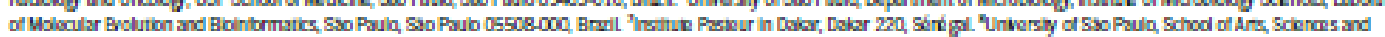

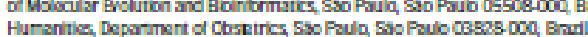

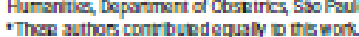

